九州大学学術情報リポジトリ

Kyushu University Institutional Repository

\title{
RANDOM COMBINED FRACTIONAL FACTORIAL DESIGNS 1 ; THEORY AND APPLICATION OF THE RANDOM COMBINED FRACTIONAL FACTORIAL DESIGNS (RACOFFD)
}

Yamakawa, Norihiro

Kasado Works, Hitachi Ltd.

https://doi.org/10.5109/13015

出版情報 : 統計数理研究. 11 (3/4)，pp. 1-38，1965-03. Research Association of Statistical Sciences

バージョン：

権利関係 : 


\title{
RANDOM COMBINED FRACTIONAL FACTORIAL DESIGNS 1 ; THEORY AND APPLICATION OF THE RANDOM COMBINED FRACTIONAL FACTORIAL DESIGNS (RACOFFD)
}

\author{
By \\ Norihiro YAMAKaWA* \\ (Received November 25, 1964)
}

\section{Introduction}

In the ordinary fractional factorial designs, an experimenter can perform $N$ trials to estimate $P$ unknown parameters $\alpha_{1}^{\prime}, \alpha_{2}^{\prime}, \cdots \cdots, \alpha_{P-1}^{\prime}$ and $\alpha_{P}^{\prime}$. These $N$ experimental points correspond to the $N$ points in the $P$ dimensional factor space (refer to G. E. P. Box [4] and [5]) which is constructed by the values of factors $x_{1}, x_{2}, \cdots, x_{P-1}$ and $x_{P}$ corresponding to the $P$ unknown parameters $\alpha_{1}^{\prime}, \alpha_{2}^{\prime}, \cdots, \alpha_{P-1}$ and $\alpha_{P}^{\prime}$. In these cases, he wishes to fix the residual factors $\xi_{1}, \xi_{2}, \cdots, \xi_{R-1}$ and $\xi_{R}$ at a point $\Xi_{0}=\left(\xi_{10}, \xi_{20}, \cdots, \xi_{R-1}, 0, \xi_{R 0}\right)$ over the whole time interval of the above $N$ trials. Although he wishes so, in the practical aspect of experiments, he can't necessarily fix these levels of the residual factors at a point in the residual factor space.

In these circumstances, we wish to infer $P$ unknown parameters $\alpha_{1}^{\prime}$, $\alpha_{2}^{\prime}, \cdots, \alpha_{P-1}^{\prime}$ and $\alpha_{P_{0}}^{\prime}$. Consequently, these situations induce several statistical problems for us. That is to say, we have $N$ points $\Xi_{1}=\left(\xi_{11}, \cdots, \xi_{R 1}\right), \Xi_{2}=$ $\left(\xi_{12}, \cdots, \xi_{R 2}\right), \cdots, \Xi_{N}=\left(\xi_{1 N}, \cdots, \xi_{R N}\right)$ on the residual factor space which is constructed by the residual factors $\xi_{1}, \xi_{2}, \cdots, \xi_{R-1}$ and $\xi_{R}$ as a noisy behaviour for our present purpose, that is the inference about the $P$ unknown parameters $\alpha_{1}^{\prime}, \alpha_{2}^{\prime}, \cdots, \alpha_{P-1}^{\prime}$ and $\alpha_{P}^{\prime}$ by the $\mathrm{N}$ trials at the points $X_{1}=\left(x_{11}\right.$, $\left.x_{21}, \cdots, x_{P 1}\right), X_{2}=\left(x_{12}, x_{22}, \cdots, x_{P 2}\right), \cdots, X_{N}=\left(x_{1 N}, x_{2 N}, \cdots, x_{P N}\right)$ on the $P$ dimensional factor space.

In order to reduce these noisy effects of residual factors to our inference of the unknown $P$ parameters $\alpha_{1}^{\prime}, \alpha_{2}^{\prime}, \cdots, \alpha_{P-1}^{\prime}$ and $\alpha_{P}^{\prime}$, the randomization procedure (refer to Kitagawa [15]) was prepared, as follows.

(1) A permutation

$$
I=\left(\begin{array}{cccc}
1 & 2 & \cdots & N \\
\pi(1) & \pi(2) & \cdots & \pi(N)
\end{array}\right)
$$

is chosen with equal probability, $1 / N$ !, from the set of all possible permutations of $N$ numbers $1,2, \cdots, N-1$ and $N$.

(2) To each permutation, $\Pi$, we perform $N$ trials $X_{\pi(1)}, X_{\pi(2)}, \cdots$,

\footnotetext{
* Kasado Works, Hitachi Ltd.
} 
$X_{\pi(N-1)}$ and $X_{\pi(N)}$.

If we can eliminate above noisy effects of the residual factors by these randomization procedures we can estimate $P(>N)$ unknown parameters by the method that the several randomized fractional factorial designs are mutually independently combined (refer to Taguchi [27] and 28]). More precisely, the following random combined fractional factorial designs can be considered.

(A) List up the factors in problem.

(B) Determine the levels of the values of these factors.

(C) Consider the interactions of these factors in above levels of factors.

(D) Divide into two groups of these factors in which two factors in different groups are not interacted each other.

(E) Allocate these two groups of factors to two fractional factorial designs with equal size, respectively.

(F) Combine randomly these two fractional factorial designs.

(G) Perform experimentations randomly with respect to the all combinations of above factors allocated in the randomly combinated fractional factorial designs.

(H) Analyse the data observed in the all combinations of all factors by the method of ordinary analysis of variances with respect to the 1st group of factors allocated in a fractional factorial designs, and analyse these same data by the same method with respect to the 2nd group of factors allocated in the 2 nd fractional factorial design.

In the same line of designs of experiment, we have several references such as Satterthwaite [25], Budne [9], Anscombe [1] and Brooks [8]. Furthermore, we have theoretical researches by Dempster [10], [11] and Takeuchi ' 29 ], [30] and [31].

The present paper will give us the results of the investigation concerning to the noisy effects as a sampling distribution from the finite populations to our inference with respect to the unknown parameters $\alpha_{1}^{\prime}, \alpha_{2}^{\prime}, \cdots, \alpha_{P-1}^{\prime}$, and $\alpha_{P}^{\prime}$.

1. Problem of the random combined fractional factorial designs (RACOFED) and resumé of main results

\subsection{Statement of the problem}

\subsubsection{Mathematical formulation}

Let us consider a linear regression model involving $P+R$ unknown parameters $\alpha_{1}^{\prime}, \cdots, \alpha_{P}^{\prime}$ and $\beta_{1}^{\prime}, \cdots, \beta_{R}^{\prime}$, such that 


$$
\zeta_{P+R}\left(x_{1}, x_{2}, \cdots, x_{P} ; \xi_{1}, \xi_{2}, \cdots, \xi_{R}\right)=\sum_{p=1}^{P} \alpha_{p}^{\prime} x_{p}+\sum_{r=1}^{R} \beta_{r}^{\prime} \xi_{r}
$$

where $x_{1}, x_{2}, \cdots, x_{P}, \xi_{1}, \xi_{2}, \cdots, \xi_{R}$ are fixed variates.

Let $D$ be a $(P+R) \times N$ design matrix

$$
D=\quad \begin{aligned}
& D_{P} \\
& D_{R}
\end{aligned}
$$

and let $D_{P}$ be a $P(<N) \times N$ design matrix in prescribed factor space and $D_{R}$ be a $R(<N) \times N$ residual design matrix in prescribed residual factor space such that

$$
D_{P}=\left(\begin{array}{cccc}
x_{11} & x_{12} & \cdots & x_{1 N} \\
x_{21} & x_{22} & \cdots & x_{2 N} \\
\cdots & \cdots & \cdots & \cdots \\
\cdots & \cdots & \cdots & \cdots \\
x_{P 1} & x_{P 2} & \cdots & x_{P N}
\end{array}\right.
$$

and

$$
D_{R}=\mid \begin{array}{cccc}
\xi_{11} & \xi_{12} & \cdots & \xi_{1 N} \\
\xi_{21} & \xi_{22} & \cdots & \xi_{2 N} \\
\cdots & \cdots & \cdots & \cdots \\
\cdots & \cdots & \cdots & \cdots \\
\xi_{R 1} & \xi_{R 2} & \cdots & \xi_{R N}
\end{array} .
$$

The observed value $y_{n}$ at a point $\left(X_{n}, \Xi_{n}\right)=\left(x_{1 n}, \cdots, x_{P_{n}} ; \xi_{1_{n}}, \cdots, \xi_{R_{n}}\right)$ is assumed to be

$$
y_{n}=\sum_{p=1}^{P} \alpha_{p}^{\prime} x_{p n}+\sum_{r=1}^{R} \beta_{r}^{\prime} \xi_{r n}+\dot{\varepsilon}_{n}
$$

where $\left\{\dot{\varepsilon}_{n}\right\} \quad(n=1,2, \cdots, N)$ is assumed to be distributed independetly according to the normal distribution $N\left(0, \sigma_{2}^{2}\right)$ with a common unknown variance $\sigma_{2}^{2}$.

We are now interested with the situation (refer to Bancroft [2], Kitagawa [14], [16] and [18]) of an experimenter for whom the model (1.1.1) is not completely specified and who may assume under his own grounds a response function of the form

$$
\zeta_{P}\left(x_{1}, x_{2}, \cdots, x_{P} ; \xi_{1}, \xi_{2}, \cdots, \xi_{R}\right)=\sum_{p=1}^{P} \alpha_{p}^{\prime} x_{p}
$$

with a certain number $P$ of unknown parameters $\alpha_{1}^{\prime}, \alpha_{2}^{\prime}, \cdots, \alpha_{P-1}^{\prime}$ and $\alpha_{P}^{\prime}$.

Under this situation he may think it better to have the least square estimates $\alpha_{1}^{\prime}, \cdots, \alpha_{P-1}$ and $\alpha_{P}^{\prime}$ under his own assumption that

$$
\beta_{1}^{\prime}=\beta_{2}^{\prime}=\cdots=\beta_{R}^{\prime}=0
$$

or 


$$
\begin{aligned}
& \xi_{11}=\xi_{12}=\cdots=\xi_{1 N} \\
& \xi_{21}=\xi_{22}=\cdots=\xi_{2 N} \\
& \cdots \cdots \cdots \cdots \cdots \cdots \cdots \\
& \cdots \cdots \cdots \cdots \cdots \cdots \\
& \xi_{R 1}=\xi_{R 2}=\cdots=\xi_{R N}
\end{aligned}
$$

the current procedure of least square estimations will give him the normal equations

$$
\sum_{q=1}^{P} a_{p q} \hat{\alpha}_{q}^{\prime}=B_{p} \quad, \quad(p=1,2, \cdots, P)
$$

where

$$
\sum_{n=1}^{N} x_{p n} x_{q n}=a_{p q} \quad, \quad(p, q=1,2, \cdots, P)
$$

and

$$
\sum_{n=1}^{N} x_{p n} y_{n}=B_{p} \quad, \quad(p=1,2, \cdots, P) .
$$

Let the rank of the $P \times P$ matrix $a_{p q} \|(p, q=1,2, \cdots, P)$ be equal to $P$, and let the $P \times P$ inverse matrix be denoted by $\left|C_{p q}\right|=\mid a_{p q}{ }^{-1}$.

If it can be assumed that (i) $\beta^{\prime}=\cdots=\beta_{R}^{\prime}=0$ or (2) $\xi_{11}=\xi_{12}=\cdots=\xi_{1 N}$ $\xi_{21}=\xi_{22}=\cdots=\xi_{2 N}, \cdots, \xi_{R 1}=\xi_{R 2}=\cdots=\xi_{R N}$ then we can estimate the unknown parameter $\alpha_{p}^{\prime}$ for a particular $p(1 \leqq p \leqq P)$ by the efficient and unbiased estimate $\hat{\alpha}_{p}^{\prime}(p=1,2, \cdots, P)$ and we can test a null hypothesis $H_{0}$ : $\alpha_{p}^{\prime}=0$ for a particular $p(1 \leqq p \leqq P)$ by appealing to statistic $F_{p}$, defined by

$$
F_{p}=(N-P)\left(\hat{\alpha}_{p}^{\prime}\right)^{2} / C_{p p} \sum_{n=1}^{N}\left(y_{n}-\sum_{p=1}^{P} \hat{\alpha}_{p}^{\prime} x_{p n}\right)^{2}
$$

which is distributed exactly according to the $F$-distribution with the pair of degrees of freedom $(1, N-P)$ under the null hypothesis.

However, in our real situation, we are not certain enough to assume (1) $\beta_{1}^{\prime}=\beta_{2}^{\prime}=\cdots=\beta_{R}^{\prime}=0$ and (2) $\xi_{11}=\xi_{12}=\cdots=\xi_{1 N}, \xi_{21}=\xi_{22}=\cdots=\xi_{2 N}, \cdots, \xi_{R 1}=$ $\xi_{R 2}=\cdots=\xi_{R N}$ and still we would appeal to the statistic $F_{p}$.

\subsubsection{The distribution function of the statistics $\hat{\alpha}_{p}^{\prime}, \sum_{n=1}^{N} e_{n}^{2}$ and others under our real situation}

Henceforth we are concerned with a model

$$
y_{n}=\sum_{p=1}^{P} \alpha_{p}^{\prime} x_{p n}+v_{n}^{\prime}+\dot{\varepsilon}_{n}
$$

under the following situations.

DEFINITION 1: (1)

$$
v_{n}^{\prime} \stackrel{d}{=} \sum_{r=1}^{R} \beta_{r}^{\prime} \xi_{r n}
$$


where (i) $\beta_{1}^{\prime}, \beta_{2}^{\prime}, \cdots, \beta_{R}^{\prime}$ are not necessarily zero and (i) $\xi_{r 1}, \xi_{r 2}, \cdots, \xi_{r N}, \quad(\boldsymbol{r}=$ $1,2, \cdots, R)$, are not necessarily equal to each other.

(2) The design matrix $D_{P}(P<N)$ is a sub-matrix

$$
D_{P}=\mid \begin{array}{cccc}
x_{11} & x_{12} & \cdots & x_{1 N} \\
x_{21} & x_{22} & \cdots & x_{2 N} \\
\cdots & \cdots & \cdots & \cdots \\
x_{P 1} & x_{P 2} & \cdots & x_{P N}
\end{array}
$$

of the complete two level $N \times N$ orthogonal array, which will be abbreviated as O. A. in the following discussions (refer to Plackett and Burman [24], Box and Hunter [5], [6], and Shimada [26] Taguchi [27])

$$
x_{p n} \|=\left(\begin{array}{ccccc}
x_{11} & \cdots & \cdots & \cdots & x_{1 N} \\
\cdots & \cdots & \cdots & \cdots & \cdots \\
x_{P 1} & \cdots & \cdots & \cdots & x_{P N} \\
x_{P+1,1} & \cdots & x_{P+1, N} \\
\cdots & \cdots & \cdots & \cdots & \cdots \\
x_{N 1} & \cdots & \cdots & \cdots & x_{N N}
\end{array}\right.
$$

where $x_{11}=x_{12}=\cdots=x_{1 N}=1$, and $x_{p n}=+1$ or $-1,(p=2, \cdots, N)$. Then we have

$$
\sum_{n=1}^{N} x_{p n}=\left\{\begin{array}{l}
N \\
0
\end{array}\right.
$$

for $p=1$

for $p=2, \cdots, N$

$(1.1 .15-2) \quad \sum_{n=1}^{N} x_{p n} x_{q n}=\left\{\begin{array}{c}N \\ 0\end{array}\right.$

for $p=q,(p, q=1,2, \cdots, N)$

for $p=q,(p, q=1,2, \cdots, N)$

and
$(1.1 .15-3)$

$$
\sum_{p=1}^{N} x_{p n} x_{p m}=\left\{\begin{array}{l}
N \\
0
\end{array}\right.
$$
for $n=m(n, m=1,2, \cdots, N)$
for $n \neq m(n, m=1,2, \cdots, N)$.

Furthermore, the alias and orthogonal relations of $r(\geq 3)$ rows can be defined by

$$
\text { (1.1.16) } \sum x_{p_{1} n} x_{p_{2} n} \cdots x_{p_{r} n}=\left\{\begin{aligned}
& N, \text { for } p_{1}, p_{2}, \cdots, p_{r} \text {-th rows are } \\
& \text { in the alias } \\
& 0, \text { for } p_{1}, p_{2}, \cdots, p_{r} \text {-th rows are } \\
& \text { in the orthogonal. }
\end{aligned}\right.
$$

Under these situation (refer to Kitagawa [15], [17], Moriguchi [20] and Mann [19]), we get the following

\section{Lemma 1: (1) We have}

$$
\begin{array}{ll}
(1.1 .17-1) & \hat{\alpha}_{p}^{\prime}=\alpha_{p}^{\prime}+\frac{1}{N} \sum_{n=1}^{N} x_{p n}\left(v_{n}^{\prime}+\dot{\varepsilon}_{n}\right), \\
(1.1 .17-2) & e_{n}=\left(v_{n}^{\prime}+\dot{\varepsilon}_{n}\right)-\sum_{p=1}^{P} x_{p n}\left(\frac{1}{N} \sum_{m=1}^{N} x_{p m}\left(v_{m}^{\prime}+\dot{\varepsilon}_{m}\right)\right)
\end{array}
$$


and

$(1.1 .17-3) \quad \sum_{n=1}^{N} e_{n}^{2}=N \sum_{p=P+1}^{N}\left(\begin{array}{l}1 \\ N\end{array} \sum_{n=1}^{N} x_{p n}\left(v_{n}^{\prime}+\dot{\varepsilon}_{n}\right)\right)^{2}$.

(2) $\frac{N}{\sigma_{2}^{2}}\left(\hat{\alpha}_{p}^{\prime}\right)^{2}$ and $\frac{1}{\sigma_{2}^{2}} \sum_{n=1}^{N} e_{n}^{2}$ are mutually independently distributed according to the non-central chi-square distribution with non-central parameters

$$
\begin{array}{ll}
\text { (1.1.18-1) } & \lambda_{1 p}=\frac{N}{2 \sigma_{2}^{2}}\left(\gamma_{p}^{\prime}+V_{p}^{\prime}\right)^{2} \\
(1.1 .18-2) & \lambda_{2}=\frac{N}{2 \sigma_{2}^{2}} \sum_{p=P+1}^{N}\left(V_{p}^{\prime}\right)^{2}
\end{array}
$$

and degrees of freedom $\phi_{1}=1, \phi_{2}=N-P$, respectively, where we put $V_{p}^{\prime}=\frac{1}{N} \sum_{n=1}^{N} x_{p n} v_{n}^{\prime}$

Proof: (1) From the definitions of the estimates, we get

$$
\begin{aligned}
\hat{\alpha}_{p}^{\prime} & =1 \sum_{n=1}^{N} x_{p n} y_{n} \\
& =\alpha_{p}^{\prime}+\frac{1}{N} \sum_{n=1}^{N} x_{p n}\left(v_{n}^{\prime}+\dot{\varepsilon}_{n}\right),
\end{aligned}
$$

and

$$
\begin{aligned}
e_{n} & =y_{n}--\sum_{p=1}^{P} \hat{x}_{p}^{\prime} x_{p n} \\
& =\left(v_{n}^{\prime}+\dot{\varepsilon_{n}}\right)-\sum_{p=1}^{P} x_{p n}\left(1 \sum_{m=1}^{N} x_{p m}\left(v_{m}^{\prime}+\dot{\varepsilon}_{m}\right)\right) .
\end{aligned}
$$

Furthermore, we get

$$
\begin{aligned}
\sum_{n=1}^{N} \dot{e}_{n}^{2} & =\sum_{n=1}^{N}\left[v_{n}^{\prime}+\dot{\varepsilon}_{n}-\sum_{p=1}^{P} x_{p n}\left\{\frac{1}{N} \sum_{m=1}^{N} x_{p m}\left(v_{m}^{\prime}+\dot{\varepsilon}_{m}\right)\right\}\right]^{2} \\
& =N \sum_{p=P+1}^{N}\left(\frac{1}{N} \sum_{m=1}^{N} x_{p m}\left(v_{m}^{\prime}+\dot{\varepsilon}_{m}\right)\right)^{2},
\end{aligned}
$$

where the 2 nd expression is reduced to the relation

$$
\begin{aligned}
& \sum_{n=1}^{N}\left(\sum_{p=1}^{N} x_{p n} X_{p}\right)^{2}=\sum_{p=1}^{N} \sum_{n=1}^{N}\left(x_{p n} X_{p}\right)^{2}+\sum_{p}^{\neq} \sum_{n=1}^{N} x_{p n} x_{q n} X_{p} X_{q} \\
& =N \sum_{p=1}^{N} X_{p}^{2} \\
& X_{p} \stackrel{d}{=} \frac{1}{N} \sum_{n=1}^{N} x_{p n}\left(v_{n}^{\prime}+\dot{\varepsilon}_{n}\right) .
\end{aligned}
$$

(2) Since the random variables $\dot{\varepsilon}_{1}, \dot{\varepsilon}_{2}, \cdots, \dot{\varepsilon}_{N-1}$ and $\dot{\varepsilon}_{N}$ are mutually independently distributed according to the normal distribution with mean zero 
and common unknown variance $\sigma_{2}^{2}$, the estimate $\hat{\alpha}_{p}^{\prime}$ is normally distributed with mean $E\left(\hat{\alpha}_{p}^{\prime}\right)=\alpha_{p}^{\prime}+V_{p}^{\prime}$ and variance $\sigma^{2}\left(\hat{\alpha}_{p}^{\prime}\right)=\sigma_{2}^{2} / N$.

Consequently, we can easily obtain the result $(\dot{2})$. The non-central parameters are easily obtained by

$$
\lambda_{1 p}=\frac{1}{2}\left\{\frac{N}{\sigma_{2}^{2}} E\left\{\left(\hat{\alpha}_{p}^{\prime}\right)^{2}\right\}-1\right\}
$$

and

$$
\lambda_{2}=\frac{N}{2}\left\{\frac{1}{\sigma_{2}^{2}} E\left(\sum e_{n}^{2}\right)-(N-P)\right\} .
$$

\subsubsection{Sampling theory from the normal populations}

On the other hand, we shall consider the distribution function under the following assumptions.

Assumption: (1) The 2nd kind of the random variables

$$
i_{n}^{\prime}=\sum_{r=1}^{d} \beta_{r}^{\prime} \xi_{r n} \quad(n=1,2, \cdots, N),
$$

where dotted notation is used to emphasize the random variable, in the model $y_{n}=\sum \alpha_{p}^{\prime} x_{p n}+\dot{v}_{n}^{\prime}+\dot{\varepsilon}_{n}, \quad(n=1,2, \cdots, N)$, are independently distributed according to the normal distribution function with mean zero and variance $\sigma_{1}^{2}$.

(2) The sums of random variables of these two kinds

$$
\dot{k}_{n} \stackrel{d}{=} \dot{v}_{n}^{\prime}+\dot{\varepsilon}_{n} \quad(n=1,2, \cdots, N)
$$

are distributed according to the normal distribution with mean zero and variance $\sigma_{k}^{2}=\sigma_{1}^{2}+\sigma_{2}^{2}=\sigma_{2}^{2}\left(1+\mu_{2}\right)$, where $\mu_{2}=\sigma_{1}^{2} / \sigma_{2}^{2}$.

For the sake of simplicity, the standardized notations such as $\alpha_{p} \stackrel{d}{=} \alpha_{p}^{\prime} / \sigma_{2}, \quad \beta_{r} \stackrel{d}{=} \beta_{r}^{\prime} / \sigma_{2}, \quad v_{\pi(n)} \stackrel{d}{=} v_{\pi(n)}{ }^{\prime} / \sigma_{2}$ and $V_{p} \stackrel{d}{=} V_{p}^{\prime} / \sigma_{2}$ may be used in the following discussions.

In these circumstances, we have

LEMMA 2: The distribution functions of the following statistics are obtained as follows.

(1) The statistic

$$
\frac{2 \lambda_{1 p}}{\mu_{2}}=\frac{N}{\mu_{2}}\left(\alpha_{p}+\frac{1}{N} \sum_{n=1}^{N} x_{p n} \dot{v}_{n}\right)^{2},
$$

in which $\lambda_{1 p}$ is the non-central parameter of the non-central chi-square variate $K_{1 p}^{2}=N \hat{\alpha}_{p}^{2}(p=1,2, \cdots, P)$ for an assigned set of given $\left\{\dot{v}_{n}\right\} \quad(n=1$, $2, \cdots, N)$, is distributed by the distribution of $\dot{v}_{n}$ according to the noncentral chi-square distribution with the non-central parameter

$$
\tau_{1 p}=\frac{N}{2 \mu_{2}} \alpha_{p}^{2},
$$

$$
(p=1,2, \cdots, P)
$$


and degree of freedom 1.

(2) The statistic

$$
\left(\chi_{1 p}^{\prime}\right)^{2}=\underset{\sigma_{1}^{2}+\sigma_{2}^{2}}{N}\left(\hat{\alpha}_{p}^{\prime}\right)^{2}
$$$$
(p=1,2, \cdots, P)
$$

is distributed according to the non-central chi-square distribution with non-central parameter

$$
\tau_{p}=\frac{N}{2\left(\sigma_{1}^{2}+\sigma_{2}^{2}\right)}\left(\alpha_{p}^{\prime}\right)^{2} \quad(p=1,2, \cdots, P)
$$

and degree of freedom 1.

(3) The statistic

$$
\frac{2 \lambda_{2}}{\mu_{2}}=\frac{N}{\mu_{2} \sigma_{2}^{2}} \sum_{p=P+1}^{N}\left(\frac{1}{N} \sum_{n=1}^{N} x_{p n} \dot{v}_{n}^{\prime}\right)^{2},
$$

in which $\lambda_{2}$ is the non-central parameter of the non-central chi-square variate $K_{2}^{2}=\frac{1}{\sigma_{2}^{2}} \sum_{n=1}^{N} e_{n}^{2}$ for a given $\left\{\dot{v}_{n}\right\}(n=1,2, \cdots, N)$, is distributed by the distribution of the sequence $\left\{\dot{v}_{n}\right\}(n=1,2, \cdots, N)$ according to the central chi-square distribution with degrees of freedom $N-P$.

(4) The statistic

$$
\chi_{2}^{2}=\frac{1}{\sigma_{1}^{2}+\sigma_{2}^{2}} \sum_{n=1}^{N} e_{n}^{2}
$$

is distributed according to the central chi-square distributions with degrees of freedom $N-P$.

(5) The statistic

$$
F_{p}^{\prime}=\frac{K_{1 p}^{2}}{K_{2}^{2}}(N-P)=\frac{\chi_{1 p}^{\prime 2}}{\chi_{2}^{2}}(N-P)
$$

is distributed according to the non-central F-distribution with non-central parameter

$$
\tau_{p}=\frac{N}{2\left(\sigma_{1}^{2}+\sigma_{2}^{2}\right)} \cdot\left(\alpha_{p}^{\prime}\right)^{2}=\frac{N}{2\left(1+\mu_{2}\right)}-\alpha_{p}^{2},
$$

where $\frac{\alpha_{p}^{\prime}}{\sigma_{2}} \stackrel{d}{=} \alpha_{p}$, and pair of degrees of freedom 1 and $N-P$.

PRoOF: (1) From the assumption (1), we have $E_{1}\left(\frac{2 \lambda_{1}}{\mu_{2}}\right)=\frac{N}{\mu_{2}} \alpha_{p}^{2}+1$, where the notation $E_{1}(\quad)$ means the expected value with respect to the normal variate $\dot{v}_{n}(n=1,2, \cdots, N)$. Consequently we get (1).

(2) Under the assumption (2), we get $E\left\{\chi_{1 p}^{\prime 2}\right\}=\frac{N}{\sigma_{1}^{2}+\sigma_{2}^{2}}\left(\alpha_{p}^{\prime}\right)^{2}+1$, where 
$E$ \} stands for the expectations with respect to the sums, which is also a normal variate with mean zero and variance $\sigma_{1}^{2}+\sigma_{2}^{2}$, of the normal variate $\dot{\varepsilon}_{n}$ and $\dot{v}_{n}^{\prime}(n=1,2, \cdots, N)$.

(3) From the assumption (1) $E_{1}\left(\begin{array}{c}2 \\ \mu_{2}\end{array} \lambda_{2}\right)=\frac{N}{\sigma_{1}^{2}} \sum_{p=P+1}^{N} E_{1}\left\{\left(\frac{1}{N} \sum x_{p n} \dot{v}_{n}^{\prime}\right)^{2}\right\}=$ $N-P$, then (3) is easily obtained.

(4) is proved in a similar way to (2).

(5) From the assumption (2), the results (2) and (4) in this lemma, it can be obtained that

$$
\begin{aligned}
F_{p}^{\prime} & =\frac{K_{1 p}^{2}(N-P)}{K_{2}^{2}}=\frac{N(N-P)}{\sigma_{2}^{2}}\left(\hat{\alpha}_{p}^{\prime}\right)^{2} / \frac{N}{\sigma_{2}^{2}} \sum_{p=P+1}^{N}\left(\frac{1}{N} \sum x_{p n} \dot{k}_{n}^{\prime}\right)_{2} \\
& =\frac{\chi_{1 p}^{\prime 2}(N-P)}{\chi_{2}^{2}}=\frac{N(N-P)}{\sigma_{1}^{2}+\sigma_{2}^{2}}\left(\hat{\alpha}_{p}^{\prime}\right)^{2} / \frac{N}{\sigma_{1}^{2}+\sigma_{2}^{2}} \sum_{p=P+1}^{N}\left(\frac{1}{N} \sum x_{p n} \dot{k}_{n}^{\prime}\right)^{2}
\end{aligned}
$$

is distributed according to the non-central $F$-distribution with non-central parameter $\tau_{p}=N \alpha_{p}^{\prime 2} / 2\left(\sigma_{1}^{2}+\sigma_{2}^{2}\right)$ and the pair of degrees of freedom 1 and $N$ $-P$, in which $\tau_{p}$ is the non-central parameter of the variate $\chi_{1 p \text {. }}^{\prime 2}$

\subsubsection{Random combined fractional factorial designs}

Let us consider the problem in our RACOFFD, in which we have a design matrix

$$
D=\left|\begin{array}{l}
D_{P} \\
D_{R}
\end{array}\right|
$$

where $D_{P}$ is a submatrix defined in the Definition 1 , and $D_{R}$ is another submatrix defined by the following definition.

Definition 2: (1) Let

$$
D_{R}=\mid \begin{array}{cccc}
\xi_{11} & \xi_{12} & \cdots & \xi_{1 N} \\
\xi_{21} & \xi_{22} & \cdots & \xi_{2 N} \\
\cdots & \cdots & \cdots & \cdots \\
\cdots & \cdots & \cdots & \cdots \\
\xi_{R 1} & \xi_{R 2} & \cdots & \xi_{R N}
\end{array}
$$

is a submatrix of the complete two level $(N-1) \times N$ orthogonal array

$$
\left|\xi_{r n}\right|=\mid \begin{array}{cccc}
\xi_{11} & \xi_{12} & \cdots & \xi_{1 N} \\
\cdots & \cdots & \cdots & \cdots \\
\xi_{R 1} & \xi_{R 2} & \cdots & \xi_{R N} \\
\xi_{R+1,1} & \xi_{R+1,2} & \cdots & \xi_{R+1, N} \\
\cdots & \cdots & \cdots & \cdots \\
\cdots & \cdots & \cdots & \cdots \\
\xi_{N-1,1} & \xi_{N-1,2} & \cdots & \xi_{N-1, N}
\end{array}
$$

which contains no row such that $\xi_{N 1}=\cdots=\xi_{N N}=1$. 
(2) The randomization procedure in our RACOFFD is defined as follows.

A) With equal probability $1 / N$ !, we choose a permutation

$$
\Pi=\left(\begin{array}{cccc}
1 & 2 & \cdots & N \\
\pi(1) & \pi(2) & \cdots & \pi(N)
\end{array}\right)
$$

from the set of all possible permutations of $N$ numbers $1,2, \cdots, N-1$ and $N$.

B) To each permutation $I I$, we define the design matrix

$$
D=\left|\begin{array}{lllc}
x_{11} & x_{12} & \cdots & x_{1 N} \\
x_{21} & x_{22} & \cdots & x_{2 N} \\
\cdots & \cdots & \cdots & \cdots \\
x_{P 1} & x_{P 2} & \cdots & x_{P N} \\
\xi_{1 \pi(1)} & \xi_{1 \pi(2)} & \cdots & \xi_{1 \pi(N)} \\
\cdots & \cdots & \cdots & \cdots \\
\xi_{R \pi(1)} & \xi_{R \pi(2)} & & \xi_{R \pi(N)}
\end{array}\right| .
$$

By virtue of these definitions of the design matrix, we get a random variable

$$
\dot{v}_{\pi(n)}=\sum_{r=1}^{R} \beta_{r} \xi_{r \pi(n)}, \quad n=1,2, \cdots, N,
$$

in our mathematical model of the observed value

$$
y_{n}=\sum_{p=1}^{P}{ }_{p}^{\prime} x_{p n}+\sigma_{2} \dot{v}_{\pi(n)}+\dot{\varepsilon}_{n}, \quad n=1,2, \cdots, N \text {. }
$$

It must be noticed that the variable $v_{\pi(n)}$ for a particular $n(1 \leqq n \leqq N)$ is fluctuated by the above randomization procedure, but the sequence of $v_{\pi(n)},\left\{v_{\pi(1)}, v_{\pi(2)}, \cdots, v_{\pi(N)}\right\}$, is a finite set under the RACOFFD situation, in which a random sampled matrix from the matrices permuted $N$ columns of a pre-randomized matrix

$$
D_{R}=\| \begin{array}{cccc}
\xi_{11} & \cdots & \cdots & \xi_{1 N} \\
\xi_{21} & \cdots & \cdots & \xi_{2 N} \\
\cdots & \cdots & \cdots & \cdots \\
\xi_{R 1} & \cdots & \cdots & \xi_{R N}
\end{array} \mid,
$$

which is sampled matrix with $R$ rows from the complete $N-1$ rows and $N$ columns O.A., is used as a sub-matrix in the design matrix.

From these discussions we get the mathematical problem in our RACOFFD situation as follows.

(1) The distribution function of $\dot{V}_{p}=\frac{1}{N} \sum_{n=1}^{N} x_{p n} \dot{v}_{\pi(n)}$ and its asymptotic property.

(2) The joint distribution function of $\left\{\dot{V}_{1}, \dot{V}_{2}, \cdots, \dot{V}_{\oplus}\right\},(\Phi<N)$, and its asymptotic property. 


\subsection{Power function in our testing hypothesis}

\subsubsection{Asymptotic sampling distribution from finite population}

In virtue of Lemma 2, we can evaluate the power of test with respect to a null hypothesis

$$
H_{0}: \boldsymbol{\alpha}_{b}^{\prime}=0
$$

for a single $p(1 \leq p \leq P)$ by appealing to the statistic $F_{p}$ defined by

$$
F_{p}=\frac{N(N-P)\left(\bar{u}_{p}^{\prime}\right)^{2}}{\sum_{n=1}^{N} e_{n}^{2}}
$$

which is distributed exactly according to $F$-distribution with the pair of degrees of freedom $[1, N-P]$ under the conditions, such that

(1) $\alpha_{p}=0$,

(2) $\dot{v}_{\pi^{(1)}}, \dot{v}_{\pi^{(2)}}, \cdots, \dot{v}_{\pi^{(N)}}$ are mutually independently distributed according to the normal distribution with mean zero and common variance $\mu_{2}=$ $\sigma_{1}^{2} / \sigma_{2}^{2}$,

(3) $\quad \dot{\varepsilon}_{1}, \cdots, \dot{\varepsilon}_{N}$ and $\dot{v}_{\pi(1)}, \cdots, \dot{v}_{\pi(N)}$ are mutually independently distributed.

On the other hand, we have the sequence $\left\{v_{\pi(1)}, v_{\pi(2)}, \cdots, v_{\pi(N)}\right\}$ in our RACOFFD situation as a finite population in which the elements are permuted by the prescribed randomization procedure in the random combination of two fractional factorial designs. In these circumstances, the 2nd condition is unsatisfied.

Henceforth, we are concerned with the asymptotic property of the sampling distribution from the finite population which is defined by the following several properties.

Definition 3: (1) The finite population is classified into $K(<N)$ classes such that $N P_{1}$ elements of $\bar{v}_{1}, N P_{2}$ elements of $\bar{v}_{2}, \cdots, N P_{K-1}$ elements of $\bar{v}_{K-1}$ and $N P_{K}$ elements of $\bar{v}_{K}$ where $\bar{v}_{k}(k=1,2, \cdots, K)$ is the values of $v_{\pi(n)}$ in the $k$-th class.

(2) The random variables

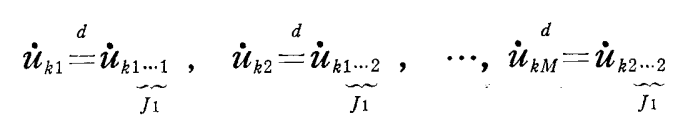

where the suffix " $k$ " stands for the $k$ th class, the 2 nd suffix 1 or 2 stands for the $\{+1$ or -1$\}$ in the lst classification into two classes, the 3rd one 1 or 2 means also $\{+1$ or -1$\}$ in the 2 nd classification into two classes, and so on, can be defined by the $2^{J_{1}}(=M<N)$ ways as random classification of the sequence $\left\{v_{\left.\pi^{(n)}\right)}\right\} \quad(n=1,2, \cdots, N)$ by the random combination of $x_{\phi n} \quad(\phi=1$, $2, \cdots, M ; n=1,2, \cdots, N)$ which is a sub-matrix of the complete $N \times N$ orthogonal array.

In these circumstances, for any assigned set of 


$$
b_{k \mu}=\quad \begin{array}{cccc}
b_{11} & b_{12} & \cdots & b_{1 M} \\
b_{21} & b_{22} & \cdots & b_{2 M} \\
\cdots & \cdots & \cdots & \cdots \\
\cdots & \cdots & \cdots & \cdots \\
b_{K 1} & b_{K 2} & \cdots & b_{K M}
\end{array}
$$

in which $b_{k \mu}=0,1,2, \cdots, 2 N P_{k} M^{-1}$, the joint probability distribution function of the set of the statistics

$$
\dot{u}_{k \mu}=\left|\begin{array}{cccc}
\dot{u}_{11} & \dot{u}_{12} & \cdots & \dot{u}_{1 M} \\
\dot{u}_{21} & \dot{u}_{22} & \cdots & \dot{u}_{2 M} \\
\cdots & \cdots & \cdots & \cdots \\
\cdots & \cdots & \cdots & \cdots \\
\dot{u}_{K 1} & \dot{u}_{K 2} & \cdots & \dot{u}_{K M}
\end{array}\right|,
$$

is given by

$$
\begin{aligned}
P\left\{\Pi \Pi \left(\dot{u}_{k \mu}\right.\right. & \left.\left.=b_{k \mu}\right)\right\} \\
& =\prod_{k=1}^{K} \frac{N P_{k} !}{\prod_{\mu=1}^{M} b_{k \mu} !} /\left(\begin{array}{c}
N ! \\
M !
\end{array}\right)^{M} .
\end{aligned}
$$

Consequently, we get

THEOREM A: For any assigned set of

$$
b_{k \mu}=\begin{array}{cccc}
b_{11} & b_{12} & \cdots & b_{1 M} \\
b_{21} & b_{22} & \cdots & b_{2 M} \\
\cdots & \cdots & \cdots & \cdots \\
\cdots & \cdots & \cdots & \cdots \\
b_{K 1} & b_{K 2} & \cdots & b_{K M}
\end{array}
$$

in which $b_{k \mu}=0,1,2, \cdots, 2 N P_{k} M^{-1}$, the joint probability distribution function of the set of the statistics

$$
\begin{aligned}
& \dot{u}_{k \mu}=\begin{array}{lllll}
\dot{u}_{11} & \dot{u}_{12} & \cdots & \dot{u}_{1 M}
\end{array} \\
& \begin{array}{llll}
\dot{u}_{21} & \dot{u}_{22} & \cdots & \dot{u}_{2 M}
\end{array} \\
& \begin{array}{llll}
\cdots & \cdots & \cdots & \ldots
\end{array} \\
& \begin{array}{cccc}
\cdots & \cdots & \cdots & \cdots \\
\dot{u}_{K 1} & \dot{u}_{K 2} & \cdots & \dot{u}_{K M}
\end{array}
\end{aligned}
$$

is given by

$$
P\left\{\Pi \Pi\left(\dot{u}_{k \mu}=b_{k \mu}\right)\right\}=C \exp \left\{-\sum_{k} \sum_{\mu} \frac{N P_{k}}{2 M} B_{k \mu}^{2}+\varepsilon_{1}^{\prime}+\varepsilon_{2}^{\prime}\right\}
$$

where

$$
C=M^{\frac{M(K-1)}{2}}(2 \pi N)^{\frac{(K-1)(M-1)}{2}}\left(\prod_{k=1}^{K} P_{k}\right)^{\frac{M-1}{2}}
$$




$$
\begin{aligned}
& \varepsilon_{1}^{\prime}=\frac{1}{12 N}\left\{\sum_{k} \frac{1}{P_{k}^{-}}-\left(1-\sum_{\mu} \frac{M}{1+B_{k \mu}}\right)+\left(M^{2}-1\right)\right\}+O\left(N^{-\frac{3}{2}}\right) \\
& \varepsilon_{2}^{\prime}=-\frac{1}{6 M} \sum_{k} \sum_{\mu} N P_{k} B_{k \mu}^{3}+\sum_{k} \sum_{\mu}\left\{\frac{N P_{k}}{12 M} B_{k \mu}^{4}-\frac{1}{4} B_{k \mu}^{2}\right\}+O\left(N^{-\frac{3}{2}}\right),
\end{aligned}
$$

where

$$
B_{k \mu} \stackrel{d}{=} \frac{M}{N P_{k}} b_{k \mu}-1
$$

\subsubsection{The power function}

As we have seen in the previous section, we have proposed the ordinary test of hypothesis $H_{0}: \alpha_{p}^{\prime}=0$ by ordinary method of $F$-test, in our RACOFFD situation. In these circumstances, we have following two kinds of error.

(i) The lst kind of error by which we reject the null hypothesis for a particular $p$ in $1 \leqq p \leqq P$, when it is true, is given by $Q_{1}$.

(ii) The 2nd kind of error by which we accept for a particular $p$ in $1 \leqq p \leqq P$, when $\alpha_{p}^{\prime} \neq 0$, is given by $Q_{2 p}=Q\left(\tau_{1 p}, \Phi, \alpha_{0}\right)$.

In virtue of Lemma 1, Lemma 2 and Theorem $A$, the lst kind of error $Q_{1}$ is equal to $\alpha_{0}$ under the asymptotic situation such that $\varepsilon^{\prime \prime}=\varepsilon_{1}^{\prime}+\varepsilon_{2}^{\prime} \simeq 0$ as we have evaluated in the previous section.

On the other hand, even if in the case that the condition $\varepsilon^{\prime \prime} \simeq 0$ is satisfied, the 2nd kind of error is changed with the change in the parameters $\tau_{p}, \Phi$ and $\alpha_{0}$. The 1st one of these is $\tau_{p}=N \alpha_{p}^{2} / 2\left(1+\mu_{2}\right)$ where $N$ is the size of experiments, $\left(\alpha_{p}^{2}=\alpha_{p}^{\prime} / \sigma_{2}\right)^{2}$ is the normalized size of the unknown parameter and $\mu_{2}=\frac{1}{\sigma_{2}^{2}}\left(\frac{1}{N} \sum_{n=1}^{N} v_{\pi(n)}^{\prime 2}\right)=\sum_{r=1}^{R}\left(\frac{\beta_{r}^{\prime}}{\sigma_{2}}\right)^{2}$ is the normalized sum of the unknown noisy parameters $\beta_{1}^{\prime}, \beta_{2}^{\prime}, \cdots, \beta_{R}^{\prime}$. The 2 nd one is the degrees of freedom of estimate of error term, and the $3 \mathrm{rd}$ is the size of test with respect to the null hypothesis $H_{0}$.

Let us consider the practical meanings of these parameters in our RACOFFD methods. The mathematical model

$$
\zeta\left(x_{1}, \cdots, x_{P} ; \xi_{1}, \cdots, \xi_{R}\right)=\left\{\sum_{P=1}^{P} \alpha_{p} x_{p}+\sum_{r=1}^{R} \beta_{r} \xi_{r}\right\},
$$

which is set up as a priori assumption by an experimenter, is an abstract model of his objective worlds. In our RACOFFD method, the experimenter decomposes this model in such a way that

$$
\zeta\left(x_{1}, \cdots, x_{P} ; \xi_{1}, \cdots, \xi_{R}\right)=\left\{\sum_{p=1}^{P} \alpha_{p} x_{p}\right\}+\left\{\sum_{r=1}^{R} \beta_{r} \xi_{r}\right\} .
$$

He then assigns the lst term $\left\{\sum \alpha_{p} x_{p}\right\}$ of this decomposed model to an O.A. and the 2 nd one $\left\{\sum \beta_{r} \xi_{r}\right\}$ to the other O.A. respectively. The parameters 
$\alpha_{p}^{2}$ and $\mu_{2}=\sum_{r=1}^{R} \beta_{r}^{2}$ are determined by these abstract objective world, $\zeta\left(x_{1}\right.$, $\left.\cdots, x_{P} ; \xi_{1}, \cdots, \xi_{R}\right)$.

In order to explore the objective world, the experimenter may decide a strategy which is composed of the parameters such as, the size of experiments $N$, the degrees of freedom $\Phi$, the size of testing hypothesis $\alpha_{0}$ and the decomposition rule into 2 groups of factors.

On the other hand, according to the original papers by Satterthwaite [25], Budne [9] and Anscombe [1], it can be seen that the random balance experimentation is useful for a kind of "screening experiments". We also recognize surely that the procedure of the method of exploring the objective worlds should contain the successive inferences after the preliminary test of the present hypothesis $H_{0}$. That is to say, our procedure should be completely established under an assumption in which the 2nd process of statistical inference is performed under by the corrected model

$$
\zeta_{\text {II }}\left(Z_{1}, \cdots, Z_{Q}\right)=\sum_{q=1}^{Q} \beta_{q} \boldsymbol{z}_{q}
$$

where $z_{1}, z_{2}, \cdots, z_{Q}$ are factors selected by test by which the non-significant factors are screened out in the 1st step of our RACOFFD method. Consequently, we shall concern to the sum of the 1 st and the 2 nd kinds of error $Q_{1}+Q_{2 p}=Q$. In these circumstances, we have the concept of the borderline test concerning the preliminary test before the final test as given by Paull [22], Bozivich, Bancroft and Hartley [7] and Kitagawa [16].

On the other hand, we have Patnaik approximation (refer to Patnaik [21] and Kitagawa [15]) of the non-central $F$-distribution such that the noncentral $F$-variate $F^{\prime}$ with non-central parameter $\tau_{p}$ and pair of degrees of freedom $(1$ and $\Phi)$ can be approximated by the central $\left(F^{\prime} / k\right)$-variate with pair of degrees of freedom $(\nu$ and $\Phi)$, where

$$
k=1+2 \tau_{p}
$$

and

$$
\nu=\frac{\left(1+2 \tau_{p}\right)^{2}}{1+4 \tau_{p}}
$$

Consequently, we can evaluate easily the power of test in the RACOFFD testing hypothesis $H_{0}$ by the tables of incomplete beta-function (Pearson [23]),

$$
P_{r}\left(F^{\prime}<F_{\bullet}^{1}\left(\alpha_{0}\right)\right) \div 1-I_{\kappa_{v}}\left(\frac{\nu}{2}, \frac{\Phi}{2}\right),
$$

where $F_{\otimes}^{1}\left(\alpha_{0}\right)$ is $100 \quad \alpha_{0}$ percent point of the $F$-distribution with pair of degrees of freedom $[1, \Phi]$ and $I_{x_{0}}(\nu / 2, \Phi / 2)$ is the incomplete beta ratio such that 


$$
I_{x_{0}}\left(\frac{\nu}{2}, \frac{\Phi}{2}\right)=\frac{\int_{1}^{x_{0}} \theta^{\frac{\nu}{2}-1}(1-\theta)^{\frac{\Phi}{2}-1} d \theta}{\int_{0}^{1} \theta^{\frac{\nu}{2}-1}(1-\theta)^{\frac{\Phi}{2}-1} d \theta},
$$

in which $x_{0}=a F_{\oplus}^{\prime}\left(\alpha_{0}\right) /\left(\Phi+a F_{\oplus}^{\prime}\left(\alpha_{0}\right)\right)$ and $a=\nu k^{-1}=\left(1+2 \tau_{p}\right) /\left(1+4 \tau_{p}\right)$.

The following figures show the 1st and 2nd kinds of error in our RACOFFD test of $H_{0}$ under the asymptotic situations. In these figures, the increasing and decreasing curves correspond to the 1 st and 2 nd kinds of error, respectively.
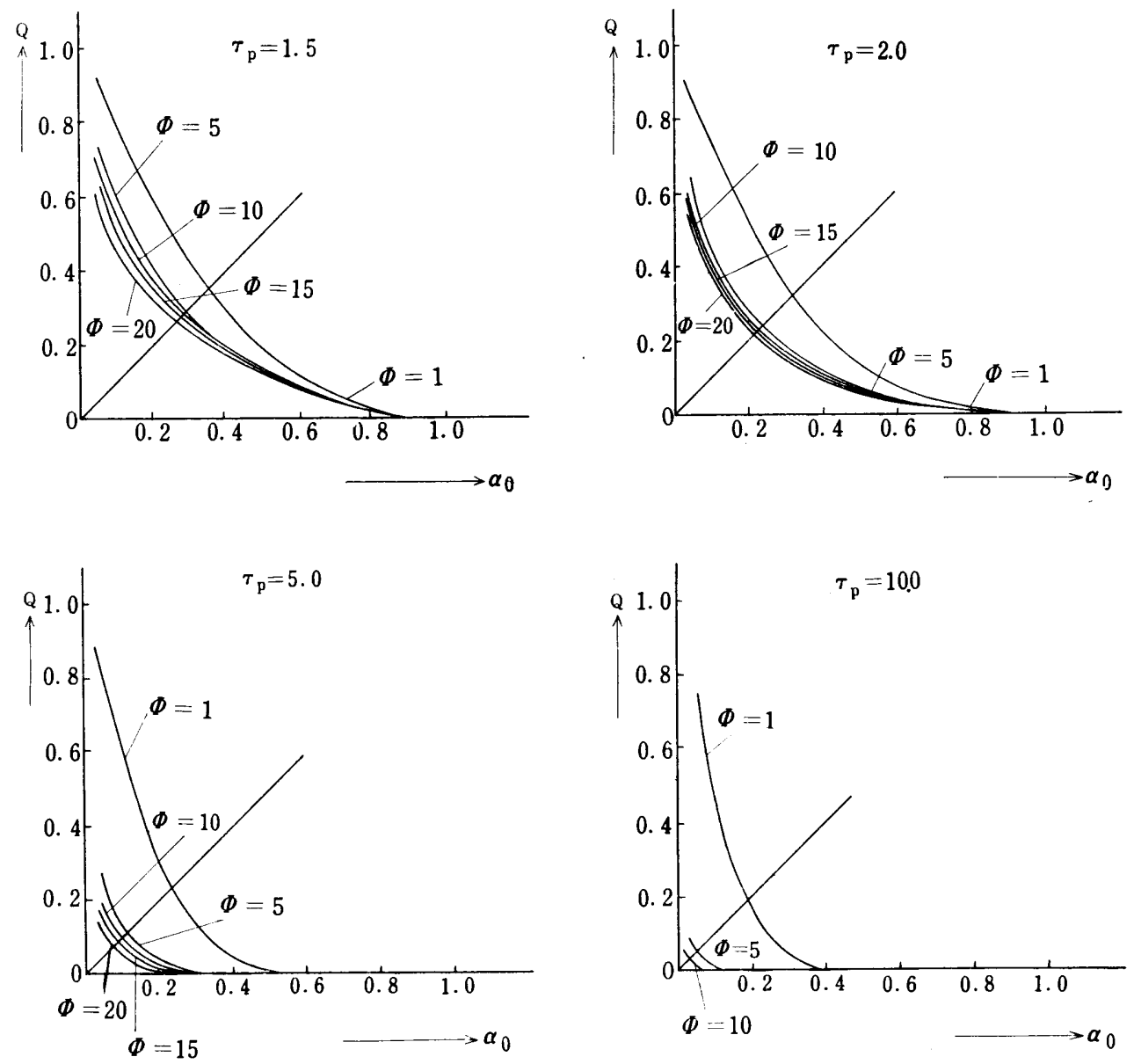

FIG. 1.2.1 1st and 2nd kinds of error

From these figures, it can be observed that the sums of these two kinds of error, in the condition that $\tau_{p}=5 \sim 10$ and $\Phi=5 \sim 10, Q=Q_{1}+Q_{2 p}$ are minimized by controlling $\alpha_{0}$ the range from 0.10 to 0.30 .

Furthermore, we get the optimal size of the experiments $N=2 \tau_{p}\left(1+\mu_{2}\right) / \alpha_{p}^{2}$, as follows. 
TABLE 1.2.1 optimal size of experiments in our RACOFFD

\begin{tabular}{r|r|r|r}
\hline$\tau_{p}$ & & & \\
\hline $1+\mu_{2}$ & 2.0 & 5.0 & 10.0 \\
\hline$\alpha_{p}^{2}$ & & & \\
\hline 2.0 & 8 & 20 & 40 \\
3.0 & 12 & 30 & 60 \\
4.0 & 16 & 40 & 80 \\
5.0 & 20 & 50 & 100 \\
\hline
\end{tabular}

\subsection{Properties of the estimates}

\subsubsection{Moments of $\lambda_{1 p}$ and $\lambda_{2}$}

The non-central parameters

$$
\lambda_{1 p}=\frac{N}{2 \sigma_{2}^{2}}\left(\alpha_{p}^{\prime}+V_{p}^{\prime}\right)^{2}
$$

and

$$
\lambda_{2}=\frac{N}{2 \sigma_{2}^{2}} \sum_{p=P+1}^{N}\left(V_{p}^{\prime}\right)^{2}
$$

of the statistics

$$
K_{1 p}=\frac{N}{\sigma_{2}^{2}}\left(\hat{\alpha}_{p}^{\prime}\right)^{2}
$$

and

$$
K_{2}=-\frac{1}{\sigma_{2}^{2}} \sum_{n=1}^{N} e_{n}^{2}
$$

contain the random variables $\dot{V}_{p}, \dot{V}_{P+1}, \dot{V}_{P+2}, \cdots, V_{N}$ each of which has a sampling distribution function from the finite population $v_{1}, v_{2}, \cdots, v_{N}$ by the randomization procedure in our RACOFFD situation.

So as to study the properties of estimates $\hat{\alpha}_{p}$ and $\sum_{n=1}^{N} e_{n}^{2}$, we shall discuss the asymptotic behavior of these moments of $\lambda_{1 p}$ and $\lambda_{2}$. The sampling moments of a statistic from a finite population can be obtained by a method due to Tukey [32], [33] and elaborated by R. Hooke [12], [13]. In this paper, a slightly extended method, which is constructed by the following lemmas concerning to the sampling moments of a finite population, is applied.

First of all, we shall give

Definition $4: A(a+b+\cdots+i)$ th degree generalized symmetric function of two way array $z_{\phi n}(\phi=1,2, \cdots, \Phi ; n=1,2, \cdots, N)$ is defined by 


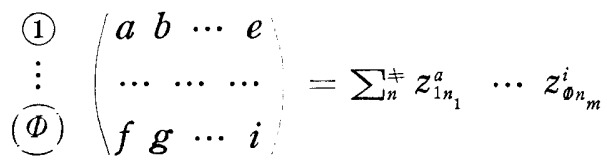

where $\sum_{n}^{\neq}$stands for the distinct sum, as a column generalized symmetric function, which will be abbreviated by c. g. s. f. here-after.

In the similar way a column generalized symmetric mean, which will be abbreviated by c. g. s. m., is defined by

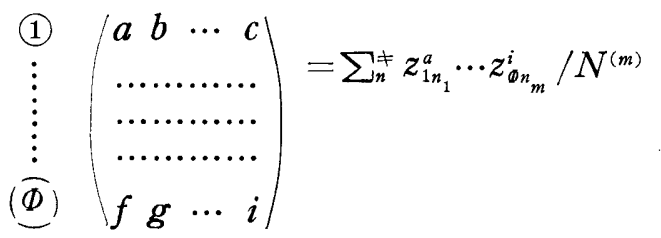

where $N^{(m)}=N \cdot(N-1) \cdots(N-m+1)$. Then we get

LEMMA 3: The product of 2 c. g. s. f. 's $\left(\varphi_{1} \times \nu_{1}\right)_{c}$ and $\left(\varphi_{2} \times \nu_{2}\right)_{c}$, which are $\varphi_{1}$ rows, $\nu_{1}$ columns and $\varphi_{2}$ rows, $\nu_{2}\left(\leqq \nu_{1}\right)$ columns c. g. s. f. 's, respectively, is given by
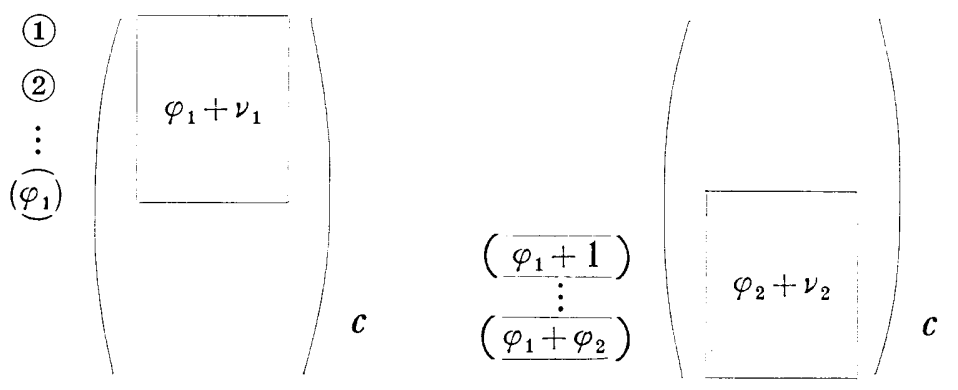

$$
\begin{aligned}
& =\Sigma^{\prime} \frac{\stackrel{1}{\vdots}}{\left(\underline{\varphi_{1}+\varphi_{2}}\right)}\left(\left(\varphi_{1}+\varphi_{2}\right) \times \nu_{1}\right)+\Sigma^{\prime \prime} \frac{\stackrel{1}{\vdots}}{\left(\underline{\varphi_{1}+\varphi_{2}}\right)}\left(\left(\varphi_{1}+\varphi_{2}\right) \times\left(\nu_{1}+1\right)\right) c \\
& +\Sigma^{\prime \prime \prime} \frac{\stackrel{1}{\vdots}}{\left(\frac{\varphi_{1}+\varphi_{2}}{)}\right.}\left(\left(\left(\varphi_{1}+\varphi_{2}\right) \times\left(\nu_{1}+2\right)\right)+\cdots+\frac{(1)}{\left(\overline{\varphi_{1}+\varphi_{2}}\right)}\left(\frac{\sqrt{\varphi_{1} \times \nu_{1}}}{\underline{\varphi_{2} \times \nu_{2}}}\right) c\right.
\end{aligned}
$$

where the following remarks should be considered.

(i) The 1st summation $\Sigma^{\prime}$ stands for the summation over all possible $\left(\varphi_{1}+\varphi_{2}\right)$ rows and $\nu_{1}$ columns $g$. $s . f$. 's, which are generated by the combination of $\nu_{2}$ in the $\nu_{1}$ positions and permutations of $\nu_{2}$ numbers.

(ii) The 2nd summation $\Sigma^{\prime \prime}$ stands for the summation over all possible $\varphi_{1}+\varphi_{2}$ rows and $\nu_{1}+1$ columns $g . s$. $f$.' 's, which are generated by the rule that the $\nu_{1}+1$ th column is chosen from the possible $\nu_{2}$ columns and $\nu_{2}-1$ possible columns are allocated in the possible $\nu_{1}$ 
columns in $\left(\begin{array}{c}\nu_{1} \\ \nu_{2}-1\end{array}\right)$ times and $\nu_{2}-1$ columns permute each other all in possible $\left(\nu_{2}-1\right)$ ! permutations.

(iii) The 3 rd summation $\Sigma^{\prime \prime \prime}$ stands for summation over all possible $\varphi_{1}+\varphi_{2}$ rows and $\nu_{1}+2$ columns g. $s$. $f$.' 's, which are generated by the rule that the possible $\left(\nu_{1}+1\right)$ th and $\left(\nu_{1}+2\right)$ th columns are chosen from the possible columns in $\left(\begin{array}{c}\nu_{2} \\ 2\end{array}\right)$ times and $\nu_{2}-2$ possible columns are allocated in the possible $\nu_{1}$ columns in $\left(\begin{array}{c}\nu_{1} \\ \nu_{2}-2\end{array}\right)$ times and $\nu_{2}-2$ columns permute each other in all possible $\left(\nu_{2}-2\right) !$ permutations.

(iv) In the similar way, the successive $c . g . s . f$.'s are generated to the term having $\nu_{1}+\nu_{2}-1$ columns.

(v) The last term is obviously

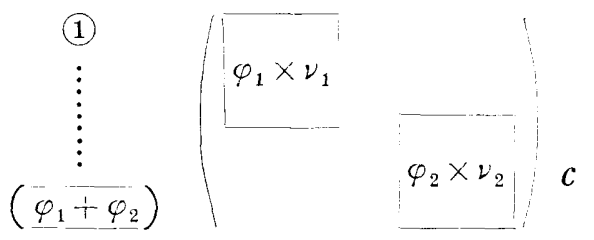

in which all columns of 2 nd c. g. s. f. are pushed out.

In the same way with those of formulas (2.2.8) and (2.2.9) in the succeeding paper [34], the proof of this lemma can be done.

Furthermore, we shall give

DEFinition 5: (1) Let us define the random pairings of a set of $N$ vectors $Z_{1}=\left(z_{11}, \cdots, z_{\oplus 1}\right), \cdots, Z_{N}=\left(z_{1 N}, \cdots, z_{{ }^{N}}\right)$ and a set of $N$ numbers $v_{\pi(1)}$,

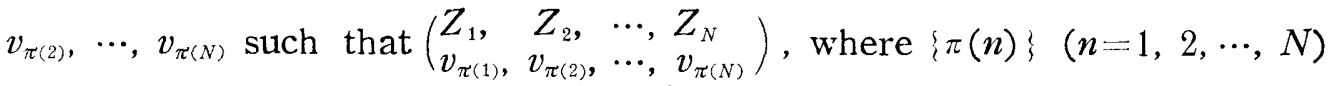
is a permutation $\Pi=\left(\begin{array}{cccc}1 & 2 & \cdots & N \\ \pi(1) & \pi(2) & \cdots & \pi(N)\end{array}\right)$, which is chosen from the possible $N$ ! permutations of $N$ numbers with equal probability $1 / N$ !.

(2) Let us define a multiplicative random pairing

$$
Z_{\phi n}=z_{\phi n} v_{\pi(n)}
$$

and generalized symmetric means, which will be abbreviated as g. s. m., in the sense given by R. Hooke [12]

$$
\left[\begin{array}{ccccc}
a & b & \cdots & \cdots & e \\
\cdots & \cdots & \cdots & \cdots & \cdots \\
\cdots & \cdots & \cdots & \cdots & \cdots \\
f & g & \cdots & \cdots & i
\end{array}\right]=\sum_{\phi}^{\neq} \sum_{n}^{\ddagger} Z_{\phi i n 1}^{a} \cdots Z_{\phi_{s} n_{\nu}}^{i} / \Phi^{(s)} N^{(v)} .
$$

Consequently we get 
LEMMA 4: The averaging over all possible g. s. m. is given by

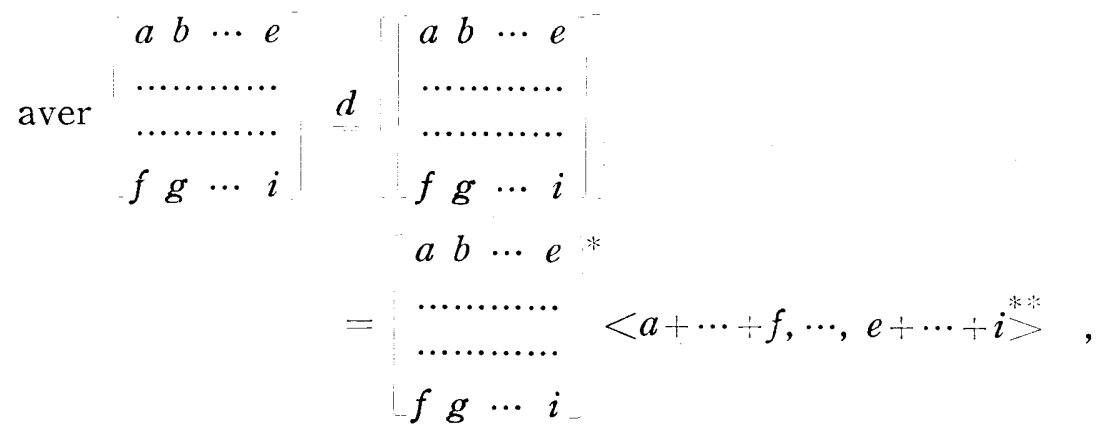

where the square bracket with one asterisk [ ] means the g. s. m. of $z_{\phi n}$ and the angle bracket with two asterisk $<>^{* *}$ means the symmetric mean of $\dot{i}_{\pi(n)}$.

The proof of this Lemma is given in the succeeding paper [34].

COLLORARY OF LEMMA 4: The averaging over all $c . g . s . m$.

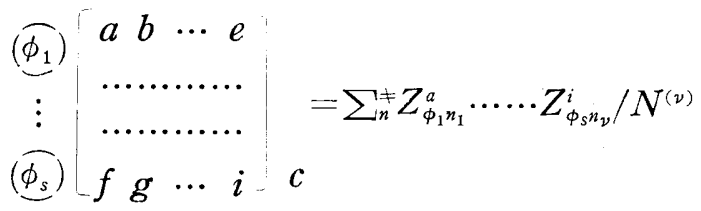

is given by

(1.3.9) aver

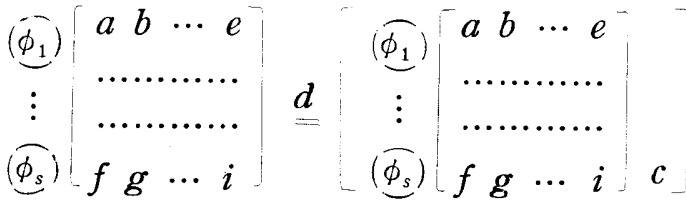

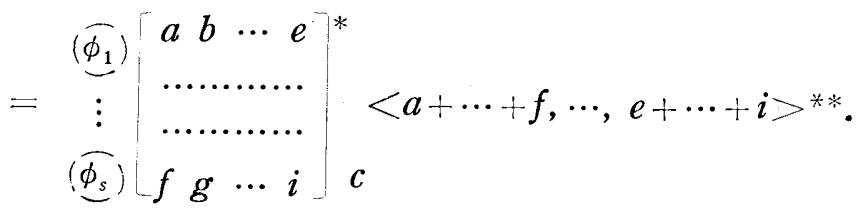

The proof of this Collorary of Lemma 4 is given in the succeeding paper [34].

In virtue of these lemmas, and some calculations in the succeeding paper, we get

THEOREM B-1: The moments of $\lambda_{1 p}$ are as follows:

$$
\begin{aligned}
& \text { aver } \lambda_{1 p}=\frac{\mu_{2}}{2}\left\{2 \tau_{1 p}+1\right\}+\Delta_{1 p}+O\left(N^{-2}\right) \\
& \text { aver } \lambda_{1 p}^{2}=\left(\frac{\mu_{2}}{2}\right)^{2}\left\{4 \tau_{1 p}^{2}+12 \tau_{1 p}+3\right\}+\Delta_{2 p}+O\left(N^{-2}\right)
\end{aligned}
$$


(1.3.10-3) aver $\lambda_{1 p}^{3}=\left(\frac{\mu_{2}}{2}\right)^{3}\left\{8 \tau_{1 p}^{3}+60 \tau_{1 p}^{2}+90 \tau_{1 p}+15\right\}+\Delta_{3 p}+O\left(N^{-2}\right)$,

and

$(1.3 .10-4)$

$$
\text { aver } \begin{aligned}
\lambda_{1 p}^{4}= & \left(\frac{\mu_{2}}{2}\right)^{4}\left\{16 \tau_{1 p}^{4}+224 \tau_{1 p}^{3}+840 \tau_{1 p}^{2}+840 \tau_{1 p}+105\right\} \\
& +\Delta_{4 p}+O\left(N^{-2}\right)
\end{aligned}
$$

where

$$
\tau_{1 p}=\frac{N \alpha_{p}^{2}}{2 \mu_{2}}
$$

$$
\Delta_{1 p}=\left(\frac{\mu_{2}}{2}\right) \frac{1}{N}
$$

$$
\Delta_{2 p}=\left(\frac{\mu_{2}}{2}\right)^{2}\left(12 \tau_{1 p}-2 \delta_{2}+6\right) \frac{1}{N}
$$

$$
\Delta_{3 p}=\left(\frac{\mu_{2}}{2}\right)^{3}\left\{60 \tau_{1 p}^{2}-\left(\frac{180}{3} \delta_{2}-180\right) \tau_{1 p}-\left(30 \delta_{2}-45\right)\right\} \frac{1}{N}
$$

\section{and}

$$
\begin{aligned}
\Delta_{4 p}= & \left(\frac{\mu_{2}}{2}\right)^{4}\left[224 \tau_{1 p}^{3}-\left\{840\left(\frac{2}{3} \delta_{2}-2\right) \tau_{1 p}^{2}\right.\right. \\
& \left.\left.+840\left(2 \delta_{2}-3\right) \tau_{1 p}+420\left(\delta_{2}-1\right)\right\}\right] \frac{1}{N}
\end{aligned}
$$

in which $\delta_{2} \stackrel{d}{=} \frac{\mu_{4}}{\mu_{2}^{2}}$.

In general, the $S(<\infty)$ th moment of $\lambda_{1 p}$ is

$$
\text { aver } \begin{aligned}
\lambda_{1 p}^{s}= & \left(\frac{\mu_{2}}{2}\right)^{s}\left\{\left(2 \tau_{1 p}\right)^{s}+\sum_{s=1}^{s} \stackrel{s}{I}(2 r-1)\left(\begin{array}{l}
2 S \\
2 s
\end{array}\right)\left(2 \tau_{1 p}\right)^{s-s}\right\} \\
& +O\left(N^{-1}\right) .
\end{aligned}
$$

THEOREM B-2: The moments of $\lambda_{2}$ are as follows:

$$
\text { aver } \lambda_{2}=\left(\frac{\mu_{2}}{2}\right) \Phi+\Delta_{1}+O\left(N^{-2}\right)
$$

$$
\text { aver } \lambda_{2}^{2}=\left(\begin{array}{c}
\mu_{2} \\
2
\end{array}\right)^{2}\left\{3 \Phi+\Phi^{(2)}\right\}+\Delta_{2}+O\left(N^{-2}\right)
$$

$$
\text { aver } \lambda_{2}^{3}=\left(\frac{\mu_{2}}{2}\right)^{3}\left\{15 \Phi+9 \Phi^{(2)}+\Phi^{(3)}\right\}+\Delta_{3}+O\left(N^{-2}\right)
$$

and

$$
\begin{aligned}
(1.3 .14-4) \quad \text { aver } \lambda_{2}^{4}= & \left(\frac{\mu_{2}}{2}\right)^{4}\left\{105 \Phi+(15 \times 4+9 \times 3) \Phi^{(2)}+6 \times 3 \Phi^{(3)}+\Phi^{(4)}\right\} \\
& +\Delta_{4}+O\left(N^{-2}\right)
\end{aligned}
$$


where

$$
\begin{array}{ll}
(1.3 .15-1) & \Delta_{1}=\frac{\mu_{2}}{2} \frac{\Phi}{N-1} \\
(1.3 .15-2) & \Delta_{2}=\left(\frac{\mu_{2}}{2}\right)^{2}\left(6-2 \delta_{2}\right) \Phi \frac{1}{N} \\
(1.3 .15-3) & \Delta_{3}=\left(\frac{\mu_{2}}{2}\right)^{3}\left\{\left(-30 \delta_{2}+45\right) \Phi-3\left(2 \delta_{2}+3\right) \Phi^{(2)}+\left(-3+4 \delta_{1}\right) \Phi^{(3)}\right\} \frac{1}{N}
\end{array}
$$

and

$$
\begin{aligned}
(1.3 .15-4) \quad \Delta_{4}= & \left(\frac{\mu_{2}}{2}\right)^{4}\left\{\left(-420 \delta_{2}+420\right) \Phi-\left(156 \delta_{2}+228\right) \Phi^{(2)}\right. \\
& \left.+\left(-2 \delta_{2}+24 \delta_{1}-18\right) 6 \Phi^{(3)}+\left(16 \delta_{1}-8\right) \Phi^{(4)}\right\} \frac{1}{N}
\end{aligned}
$$

in which $\delta_{1} \stackrel{d}{=} \frac{\mu_{3}^{2}}{\mu_{2}^{3}} r_{3} \quad, \quad \delta_{2} \stackrel{d}{=} \frac{\mu_{4}}{\mu_{2}^{2}}$.

In general, the $K(<\infty)$ th moment of $\lambda_{2}$ is

$$
\text { (1.3.16) } \quad \text { aver } \lambda_{2}^{K}=\left(\frac{\mu_{2}}{2}\right)^{K} \sum_{\phi} c_{\phi}\left\{<2^{K}>^{* *}\right\} \Phi^{(\phi)}+O\left(N^{-1}\right) \text {, }
$$

where $c_{\phi}\left\{<2^{K}>^{* *}\right\}$ stands for the numerical coefficient of the symmetric mean $\left\langle 2^{K}\right\rangle^{* *}$.

Consequently, we can evaluate the asymptotic properties of the moments of the statistics $\lambda_{1 p}$ and $\lambda_{2}$.

\subsubsection{Properties of the estimates}

Let us consider the properties of the estimates. First of all, for the original observation $y_{n}=\sum_{p=1}^{p} \alpha_{p}^{\prime} x_{p n}+\dot{v}_{\pi^{\prime}(n)}^{\prime}+\dot{\varepsilon}_{n}$ after the randomization procedure, we have

$$
\begin{aligned}
\xi\left(y_{n}\right) & \stackrel{d}{=} \operatorname{aver}\left\{E\left(y_{n}\right)\right\} \\
& =\operatorname{aver}\left(\sum_{p} x_{p}^{\prime} x_{p n}\right)+\operatorname{aver}\left\{\dot{v}_{\pi(n)}^{\prime}\right\} \\
& =\sum_{p} \alpha_{p}^{\prime} x_{p n} \\
\sigma^{2}\left(y_{n}\right) & \stackrel{d}{=} \xi\left\{\left(y_{n}-\left(\xi\left(y_{n}\right)\right)^{2}\right\}\right. \\
& \left.=\operatorname{aver} E\left\{\dot{v}_{\pi^{\prime}(n)}^{2}+\dot{\varepsilon}_{n}^{2}+2 \dot{v}_{\pi^{\prime}(n)}^{\prime} \dot{\varepsilon}_{n}\right)\right\} \\
& =\operatorname{aver}\left(\dot{v}_{\pi^{\prime}(n)}^{2}\right)+E\left(\dot{\varepsilon}_{n}^{2}\right) \\
& =\sigma_{1}^{2}+\sigma_{2}^{2}
\end{aligned}
$$

and for the covariance of $y_{n}$ and $y_{m}$ is

$$
\sigma^{2}\left(y_{n}, y_{m}\right) \stackrel{d}{=}\left[\left\{\left(y_{n}-\Im\left(y_{n}\right)\right)\left(y_{m}-\left[\left(y_{m}\right)\right)\right\}\right.\right.
$$




$$
\begin{aligned}
& =\operatorname{aver}\left\{\dot{v}_{\pi(n)} \dot{v}_{\pi(m)}{ }^{\prime}\right\} \\
& =\sum_{r, s} \beta_{r}^{\prime} \beta_{s}^{\prime} \operatorname{aver}\left(\dot{\xi}_{r \pi(n)} \dot{\xi}_{s \pi(m)}\right) .
\end{aligned}
$$

Substituting the results of g. s. m. 's of O.A. in chapter 2 of the succeeding paper [34], the averaging value of the product $\dot{\xi}_{r \pi(n)} \dot{\xi}_{s \pi(m)}$ is obtained as follows,

$$
\text { aver } \begin{aligned}
\dot{\xi}_{r \pi(n)} \dot{\xi}_{s \pi(m)} & =\left[\begin{array}{cc}
1 & 1 \\
- & -
\end{array}\right]^{*}=-\frac{1}{N-1} \quad, \text { for } r=s \\
& =\left[\begin{array}{cc}
1 & - \\
- & 1
\end{array}\right]^{*}=0^{*} \quad, \text { for } r \rightarrow s \quad .
\end{aligned}
$$

Then we get

$$
\sigma^{2}\left(y_{n}, y_{m}\right)=\frac{-1}{N-1} \sum_{r=1}^{R} \beta_{r}^{\prime 2}=\frac{-1}{N-1} \sigma_{1}^{2}
$$

From these results, it can be observed that the original data $y_{n}(n=1$, $2, \cdots, N)$ in our RACOFFD method are mutually correlatedly distributed with mean $\sum_{p=1}^{P} \alpha_{p}^{\prime} x_{p n}$, variance $\sigma_{1}^{2}+\sigma_{2}^{2}$ and covariance $-\sigma_{1}^{2} / N-1$.

Furthermore, for the least square estimates

$$
\begin{aligned}
\hat{x}_{p}^{\prime} & =\alpha_{p}^{\prime}+\frac{1}{N} \sum x_{p n} \dot{v}_{\pi(n)}^{\prime}+\frac{1}{N} \sum x_{p n} \dot{\varepsilon}_{n} \\
& \stackrel{d}{=} \alpha_{p}^{\prime}+\dot{V}_{p}^{\prime}+\dot{\eta}_{p},
\end{aligned}
$$

the expected value is given by

$$
\begin{aligned}
\xi\left(\hat{\alpha}_{p}^{\prime}\right) & \stackrel{d}{=} \text { aver } E\left(\alpha_{p}^{\prime}+\frac{1}{N} \sum x_{p n} \dot{v}_{\pi^{(}(n)}^{\prime}+\frac{1}{N} \sum x_{p n} \dot{\varepsilon}_{n}\right) \\
& =\alpha_{p \cdot}^{\prime} .
\end{aligned}
$$

For even $K$, we have

$$
\begin{aligned}
\mathfrak{F}\left(\hat{\alpha}_{p}^{\prime K}\right)= & \operatorname{aver} E \sum_{k=0}^{K}\left(\begin{array}{c}
K \\
k
\end{array}\right)\left(\alpha_{p}^{\prime}+\dot{V}_{p}^{\prime}\right)^{k} \dot{\eta}_{p}^{K-k} \\
& =\left(\frac{\sigma_{2}^{2}}{N}\right)^{\frac{K}{2}} \sum_{s=0}^{K}\left(\begin{array}{l}
K \\
2 s
\end{array}\right) 2^{s} \text { aver } \lambda_{1 p}^{s} E\left\{\left(\frac{\dot{\varepsilon}_{n}}{\sigma_{2}}\right)^{K-2 s}\right\} .
\end{aligned}
$$

For odd $K$, the $K$ th moment about mean is

$$
\varepsilon\left\{\left(\hat{\alpha}_{p}^{\prime}-\alpha_{p}^{\prime}\right)^{K}\right\}=0 \text {. }
$$

Consequently, we get

$$
\left(\tilde{S}\left(\hat{x}_{p}^{\prime}\right)^{2}=\frac{\sigma_{2}^{2}}{N}\left(2 \text { aver } \lambda_{1 p}+1\right)\right.
$$


and

$$
\left(S\left(\hat{\alpha}_{p}^{\prime}\right)^{4}=\left(\frac{\sigma_{2}^{2}}{N}\right)^{2}\left(2^{2} \text { aver } \lambda_{1 p}^{2}+\left(\begin{array}{l}
4 \\
2
\end{array}\right) 2 \text { aver } \lambda_{1 p}+3\right) .\right.
$$

In these circumstances, we get easily the momonts of $\hat{a}_{p}^{\prime}$ as the moments of normal variate with mean $\xi\left(\hat{u}_{p}^{\prime}\right)=\alpha_{p}^{\prime}$ and variance

$$
\begin{aligned}
\operatorname{c}\left\{\left(\hat{\alpha}_{p}^{\prime}-\alpha_{p}^{\prime}\right)^{2}\right\} & =\frac{\sigma_{2}^{2}}{N} 2 \text { aver } \lambda_{1 p}+\frac{\sigma_{2}^{2}}{N}-\alpha_{p}^{\prime 2} \\
& =\frac{\sigma_{2}^{2}}{N}\left\{\mu_{2}\left(2 \tau_{1 p}+1\right)\right\}+\frac{\sigma_{2}^{2}}{N}-\alpha_{p}^{\prime 2} \\
& =\left(\sigma_{1}^{2}+\sigma_{2}^{2}\right) \frac{1}{N}
\end{aligned}
$$

under the condition that the departures of the asymptotic moments of $\lambda_{1 p}$ from the exact moments $\Delta_{i p}(i=1,2,3$ and 4$)$ for the 1 st, the $2 \mathrm{nd}$, the $3 \mathrm{rd}$ and the 4 th moments are negligible.

By virtue of 'Theorem B-2 and lemmas, we have the first four asymptotic moments of statistic, $\sum e_{n}^{2} / \sigma_{1}^{2}+\sigma_{2}^{2}$, which is the estimate of the error term, as those moments of the central chi-square distribution with the degrees of freedom $\Phi=N-P$. Consequently, we can easily obtain

$$
\begin{aligned}
& {\left[\hat{\xi}\left(\sum_{n=1}^{N} e_{n}^{2}\right)=\left(\sigma_{1}^{2}+\sigma_{2}^{2}\right)(N-P)+O\left(N^{-1}\right)\right.} \\
& \left\{\left(\sum_{n=1}^{N} e_{n}^{2}\right)^{2}\right\}=\left(\sigma_{1}^{2}+\sigma_{2}^{2}\right)^{2} 2(N-P)+O\left(N^{-1}\right)
\end{aligned}
$$

and so on. Furthermore, the confidence interval of parameter, $\sigma_{1}^{2}+\sigma_{2}^{2}$, can be obtained in the crdinary method by the chi-square distribution function with the degrees of freedom $\Phi=N-P$ under the conditicn in which the departures of the asymptotic monents of $\lambda_{2}$ from the exact moments of $\lambda_{2}$, $\Delta_{i}(i=1,2,3$ and 4$)$ are negligible.

\section{A practical application and simulations}

\subsection{An example of the practical applications of RACOFFD method}

\subsubsection{Aim of the experiments}

An example may be taken in reference to plug welding. The aim of the experiments is to find out the effects of following factors to a response, "strength" of the metal welded by the method of plug welding. The shape of these specimens, by which we have observed the strength of welded metals, is sketched in Fig. 2-1. In Fig. 2-1, in which (a) is the upper view of the specimen and (b) is the side view, the part $A$ is the welded 


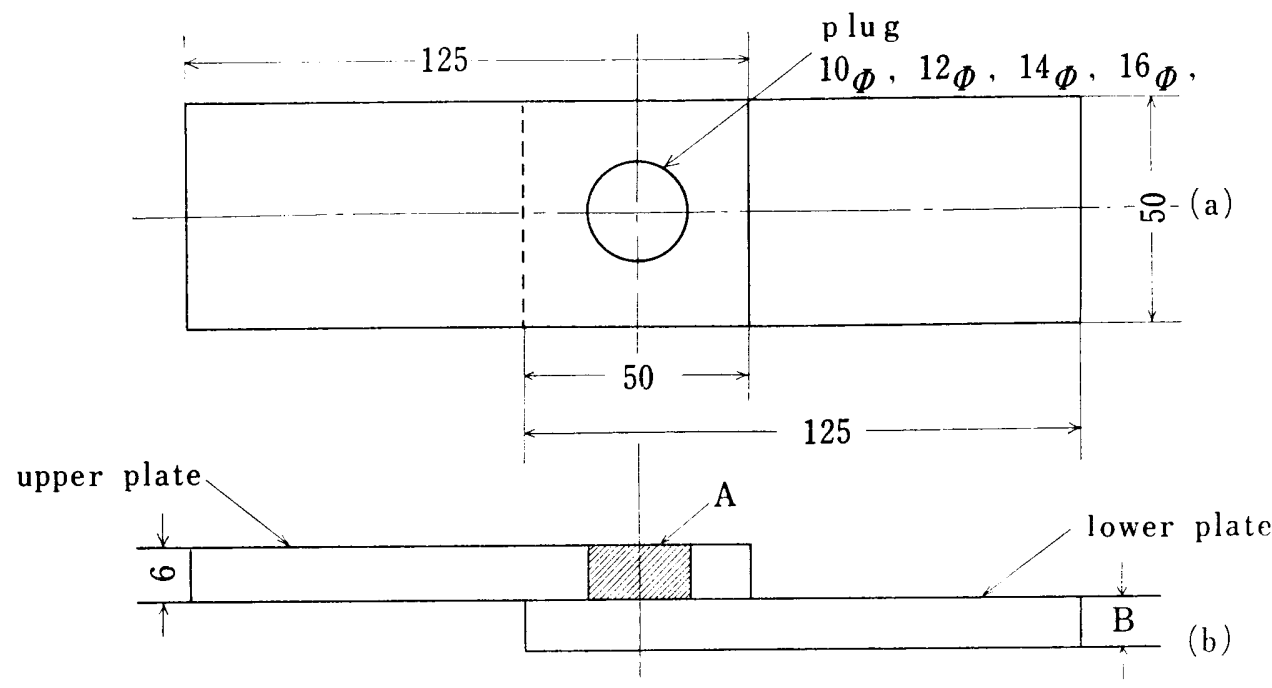

FIG. 2-1 The shape of specimens

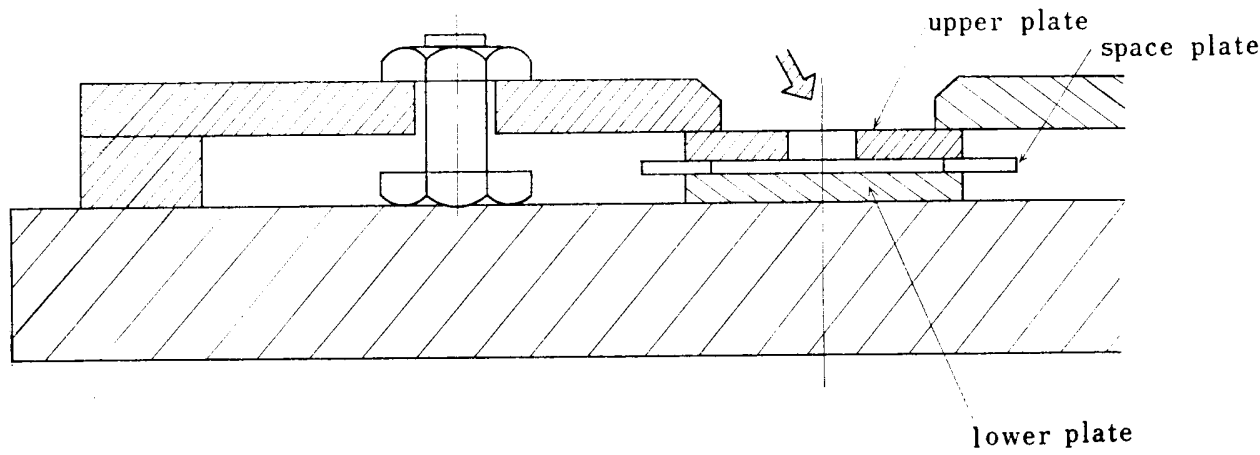

FIG. 2-2 Welding apparatus of the specimens

part of this specimen, which is the plug such that the pre-welding state of the part of upper plate in this figure is a hole.

In Fig. 2-2, the side view of welding apparatus of experiments in which the deposite metal fills out in the arrowed part under the controlled states

TABLE 2-1 Factors and those levels

\begin{tabular}{|c|c|c|c|c|c|c|}
\hline \multirow{2}{*}{ Factor } & \multirow{2}{*}{ Notation } & \multicolumn{4}{|c|}{ levels to be controlled } & \multirow{2}{*}{ dimension } \\
\hline & & 0 & 1 & 2 & 3 & \\
\hline $\begin{array}{l}\text { Plug dianeter } \\
\text { Thickness of lower plate } \\
\text { Gas ratio } \\
\text { Paintings } \\
\text { Arc voltage } \\
\text { Gap } \\
\text { Maker } \\
\text { Welding current }\end{array}$ & $\begin{array}{l}\text { A } \\
B \\
C \\
D \\
H \\
G \\
F \\
\text { E }\end{array}$ & $\begin{array}{c}10 \\
6 \\
15: 0 \\
\text { No } \\
30 \\
0 \\
\mathrm{~F}_{1} \\
250\end{array}$ & $\begin{array}{c}12 \\
10 \\
15: 3 \\
\text { Paint } \\
40 \\
0.8 \\
F_{2} \\
300\end{array}$ & 350 & 16 & $\begin{array}{l}\mathrm{mm} \\
\mathrm{mm} \\
\overline{\mathrm{Volt}} \\
\mathrm{mm} \\
\text { Amp. }\end{array}$ \\
\hline
\end{tabular}


in the following factor combinations designed by the RACOFFD.

We shall tabulate the factors and these levels to be controlled which have to be investigated by the experimental method in Table 2-1. With respect to these factors and those levels, we have the following remarks:

(1) Diameter of the plug which is the welded part is represented by the dimension "A " in Fig. 2-1 and 2-2.

(2) The thickness of the lower plate is represented by the dimension " $\mathrm{B}$ " in Fig. 2-1.

(3) Gas ratio is the mixing ratio of two kinds of gases, such that " $\mathrm{O}_{2}$ " gas content versus " $\mathrm{CO}_{2}$ " gas content.

(4) "Painting" means two states of specimens before the welding operation that the both osculating planes are painted or not.

(5) "Maker" means the maker of materials used in the welding operation.

(6) The gap of both plates is controlled by the system shown in Fig. 2-2, where the space plates generate the gap.

(7) "Welding current" and "arc voltage" are the controllable variables in the welding procedure.

(8) The responses of these experiments are observed by a 20-ton Amslar strength testing machine.

After some considerations concerning to the phenomena in the factor space constructed by above factors, we separate the factors into 2 groups such that the 1st group of factors contains $A, B, C, D$ and the 2 nd group of factors contains $E, F, G, H$. In virtue of the decomposition of factors $A$, $B, \cdots, G$ and $H$, we can easily assign these factors in our random combined fractional factorial designs with two levels and size $N=32$.

\subsubsection{Design matrix and experimental results}

We can show the design matrix with the responses as in Table $2-2$, in which the prescribed factors $A, B, \cdots, G$ and $H$ are allocated in the RACOFFD with two levels and size $N=32$ (The procedure of allocation of factors in the design matrix is described in the end of introduction of this paper). In this table, the two levels of factors are denoted in " 0 " and " 1 ", and the four levels of factors, $A$ and $E$, are denoted in " 00 ", " 01 ", " 10 " and " 11 " corresponding to " 1 ", “ 2 ", " 3 " and " 4 " levels, respectively. The strengthes of the specimens, which are the responses of the present experiments, are given in the last column.

\subsubsection{Analysis of the Data}

From the results of experiments, which are presented in Table 2-2, we can analyse variance of these responses into the effects of the 1st group factors by the ordinary procedure of analysis of variances under assumption that the effects of the 2 nd group factors are mutually independently distributed 
TABLE 2-2 Design matrix and results of plug welding experimets

\begin{tabular}{|c|c|c|c|c|c|c|c|c|c|c|c|}
\hline \multirow{2}{*}{ No. } & \multicolumn{4}{|c|}{ 1st group } & & \multicolumn{5}{|c|}{ 2nd group } & \multirow{2}{*}{$\begin{array}{l}\text { Response } \\
\text { strength }\end{array}$} \\
\hline & \multicolumn{2}{|c|}{ A } & \multirow{2}{*}{$\frac{B}{0}$} & \multirow{2}{*}{$\begin{array}{l}\text { C } \\
0\end{array}$} & \multirow{2}{*}{$\begin{array}{l}\mathrm{D} \\
0\end{array}$} & \multicolumn{2}{|c|}{$\mathrm{E}$} & \multirow{2}{*}{$\frac{F}{0}$} & \multirow{2}{*}{$\begin{array}{l}\text { G } \\
1\end{array}$} & \multirow{2}{*}{$\begin{array}{l}\mathrm{H} \\
1\end{array}$} & \\
\hline 1 & 0 & 0 & & & & 1 & 1 & & & & 4.75 \\
\hline 2 & 0 & 0 & 0 & 0 & 1 & 1 & 0 & 1 & 1 & 1 & 5.50 \\
\hline 3 & 0 & 0 & 0 & 1 & 0 & 1 & 0 & 0 & 1 & 1 & 6.70 \\
\hline 4 & 0 & 0 & 0 & 1 & 1 & 0 & 1 & 0 & 1. & 0 & 3.95 \\
\hline 5 & 0 & 0 & 1 & 1 & 1 & 0 & 1 & 1 & 0 & 1 & 3.19 \\
\hline 6 & 0 & 0 & 1 & 1 & 0 & 0 & 0 & 0 & 1 & 0 & 2.69 \\
\hline 7 & 0 & 0 & 1 & 0 & 1 & 1 & 0 & 0 & 0 & 0 & 6.20 \\
\hline 8 & 0 & 0 & 1 & 0 & 0 & 1 & 0 & 0 & 0 & 1 & 6.30 \\
\hline 9 & 0 & 1 & 1 & 1 & 1 & 0 & 0 & 0 & 0 & 1 & 4.90 \\
\hline 10 & 0 & 1 & 1 & 1 & 0 & 0 & 1 & 0 & 0 & 1 & 3.30 \\
\hline 11 & 0 & 1 & 1 & 0 & 1 & 1 & 1 & 0 & 0 & 0 & 4.45 \\
\hline 12 & 0 & 1 & 1 & 0 & 0 & 0 & 0 & 0 & 0 & 0 & 3.10 \\
\hline 13 & 0 & 1 & 0 & 0 & 0 & 1 & 1 & 0 & 0 & 1 & 5.05 \\
\hline 14 & 0 & 1 & 0 & 0 & 1 & 1 & 1 & 1 & 1 & 1 & 4.75 \\
\hline 15 & 0 & 1 & 0 & 1 & 0 & 0 & 0 & 1 & 1 & 1 & 3.65 \\
\hline 16 & 0 & 1 & 0 & 1 & 1 & 0 & 0 & 1 & 0 & 0 & 5.65 \\
\hline 17 & 1 & 1 & 1 & 1 & 1 & 0 & 1 & 1 & 1 & 1 & 5.80 \\
\hline 18 & 1 & 1 & 1 & 1 & 0 & 1 & 1 & 1 & 0 & 0 & 7.85 \\
\hline 19 & 1 & 1 & 1 & 0 & 1 & 0 & 0 & 1 & 1 & 0 & 6.70 \\
\hline 20 & 1 & 1 & 1 & 0 & 0 & 0 & 1 & 0 & 1 & 1 & 5.00 \\
\hline 21 & 1 & 1 & 0 & 0 & 0 & 1 & 0 & 1 & 0 & 0 & 6.05 \\
\hline 22 & 1 & 1 & 0 & 0 & 1 & 1 & 1 & 1 & 0 & 1 & 4.65 \\
\hline 23 & 1 & 1 & 0 & 1 & 0 & 0 & 1 & 0 & 0 & 0 & 4.97 \\
\hline 24 & 1 & 1 & 0 & 1 & 1 & 1 & 1 & 0 & 1 & 0 & 6.98 \\
\hline 25 & 1 & 0 & 0 & 0 & 0 & 0 & 0 & 0 & 1 & 1 & 5.95 \\
\hline 26 & 1 & 0 & 0 & 0 & 1 & 0 & 0 & 1 & 0 & 1 & 6.23 \\
\hline 27 & 1 & 0 & 0 & 1 & 0 & 1 & 0 & 1 & 1 & 0 & 7.30 \\
\hline 28 & 1 & 0 & 0 & 1 & 1 & 0 & 1 & 1 & 1 & 0 & 7.20 \\
\hline 29 & 1 & 0 & 1 & 1 & 1 & 0 & 1 & 1 & 1 & 0 & 8.00 \\
\hline 30 & 1 & 0 & 1 & 1 & 0 & 1 & 0 & 0 & 1 & 0 & 8.65 \\
\hline 31 & 1 & 0 & 1 & 0 & 1 & 1 & 1 & 1 & 0 & 0 & 8.43 \\
\hline 32 & 1 & 0 & 1 & 0 & 0 & 1 & 0 & 1 & 0 & 1 & 10.05 \\
\hline
\end{tabular}

TABLE 2-3 Analysis of variance-1st group factors-

\begin{tabular}{c|r|r|r|r|r}
\hline Factors & S. S & D. F & M. S & $F_{0}$ & $F_{\mathrm{f}_{2}}^{f_{1}(0.20)}$ \\
\hline A & 5,261 & 3 & 1,754 & 12 & 1.78 \\
B & 78 & 1 & 78 & 0.5 & 1.82 \\
C & 18 & 1 & 18 & 0.1 & 1.82 \\
D & 3 & 1 & 3 & 0.02 & 1.82 \\
A $\times$ B & 1,160 & 3 & 387 & 2.6 & 1.78 \\
A $\times$ C & 618 & 3 & 206 & 1.4 & 1.78 \\
A $\times$ D & 367 & 3 & 123 & 0.8 & 1.78 \\
B C & 276 & 1 & 276 & 1.9 & 1.82 \\
B $\times$ D & 1 & 1 & 1 & - & 1.82 \\
C $\times$ D & 0.2 & 1 & 0.2 & - & \\
\hline Error & 1,901 & 14 & 146 & & \\
Total & 9,684 & 31 & & & \\
\hline
\end{tabular}

according to the normal distribution, vicé versa. In Table 2-3 and 2-4, we shall present the results of analysis of variance concerning to the 1 st and 2nd group factors, respectively.

In these analysis variance tables, we shall abbreviate $S . S$. to show the 
TABLE 2-4 Analysis of variance-2nd group factors-

\begin{tabular}{|c|c|c|c|c|c|}
\hline Factors & S.S & D. F & M. S & Fo & $\mathrm{F}_{\mathrm{f}^{2}}^{\mathrm{f}_{1}}(0.20)$ \\
\hline $\begin{array}{c}\mathrm{E} \\
\mathrm{F} \\
\mathrm{G} \\
\mathrm{H} \\
\mathrm{E} \times \mathrm{F} \\
\mathrm{E} \times \mathrm{G} \\
\mathrm{E} \times \mathrm{H} \\
\mathrm{F} \times \mathrm{G} \\
\mathrm{F} \times \mathrm{H} \\
\mathrm{G} \times \mathrm{H}\end{array}$ & $\begin{array}{c}2,383 \\
1,012.5 \\
98 \\
480.5 \\
235 \\
230.5 \\
1,110 \\
162 \\
648 \\
220.5\end{array}$ & $\begin{array}{l}3 \\
1 \\
1 \\
1 \\
3 \\
3 \\
3 \\
1 \\
1 \\
1\end{array}$ & $\begin{array}{c}794 \\
1,012.5 \\
98 \\
480.5 \\
78.3 \\
76.5 \\
370 \\
162 \\
648 \\
220.5\end{array}$ & $\begin{array}{l}3.3 \\
4.2 \\
0.4 \\
2.0 \\
0.3 \\
0.3 \\
1.6 \\
0.7 \\
2.7 \\
0.9\end{array}$ & $\begin{array}{l}1.78 \\
1.82 \\
1.82 \\
1.82 \\
1.78 \\
1.78 \\
1.78 \\
1.82 \\
1.82 \\
1.82\end{array}$ \\
\hline $\begin{array}{l}\text { Error } \\
\text { Total }\end{array}$ & $\begin{array}{l}3,103.5 \\
9,683.5\end{array}$ & $\begin{array}{l}14 \\
31\end{array}$ & 238.7 & & \\
\hline
\end{tabular}

sums of squares, D.F. to show the degrees of freedom, M.S. to show the mean squares, $F_{0}$ to show the observed $\boldsymbol{F}$ and $F_{f_{2}}^{f_{1}}(0.20)$ to show the $20 \%$ point in $F$-distribution with pair of degrees of freedom $f_{1}$ and $f_{2}$.

In these analysis of variance tables, Table $2-3$ and $2-4$, the curves of the several significant effects of factors in the analysis of variance test are given in Fig. 2-3, 2-4, 2-5, 2-6, 2-7, 2-8 and 2-9. These figures represent effective valuable informations concerning to the aim of these experiments, as follows.

(1) Fig 2-3 gives the information that the strength of welded metals increases almost linearly as the plug diameters increase and this is quite reasonable as may be found in our preliminary considerations on the physical aspects of this phenomena.

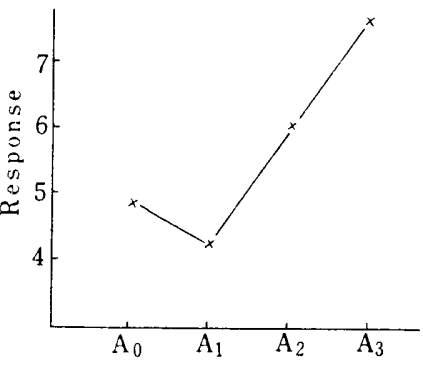

FIG. 2-3 Response to A

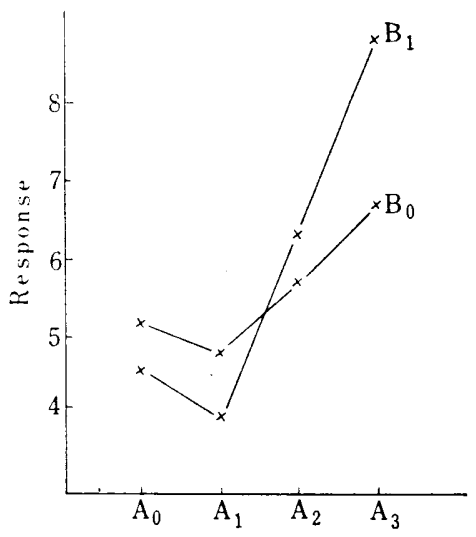

FIG. 2-4 Interation of $\mathrm{A} \times \mathrm{B}$

(2) In Fig. 2-4, we get an information concerning that interaction between $A$ and $B$ such that the effect of factor $A$ in $\mathrm{B}_{0}$ is less than the effect of $A$ in $B_{1}$.

(3) The interaction of $B$ and $C$ is shown in Fig. 2-5, which shows that the effect of factor $B$ in $C_{1}$ is smaller than corresponding effect in $C_{0}$.

(4) The main effect of factor $E$ is shown in Fig. 2-6, which gives the effect of welding current is represented in a smooth curve. 


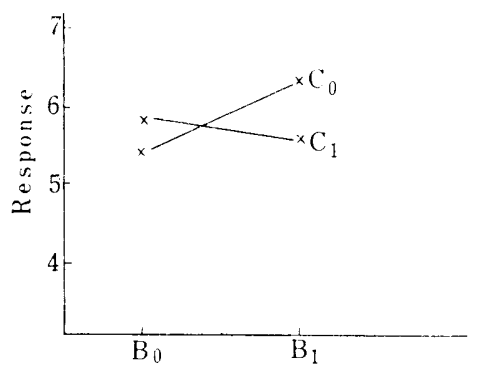

FIG. 2-5 Interation of $\mathrm{C}$ and $\mathrm{B}$

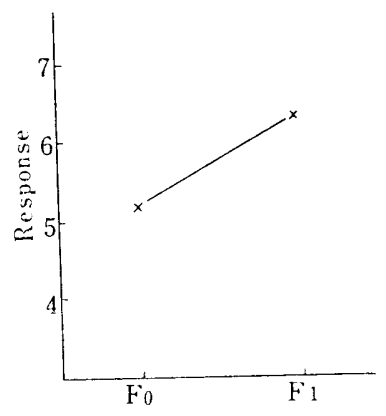

FIG. 2-7 Fator F

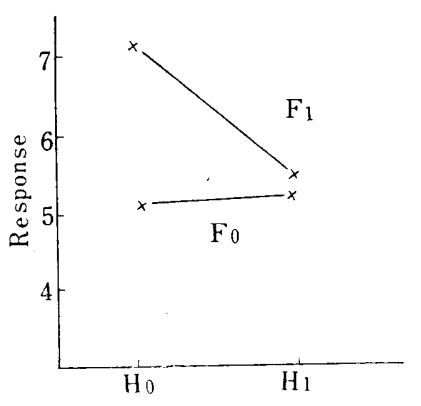

FIG. 2-9 Interaction $\mathrm{H} \times \mathrm{F}$

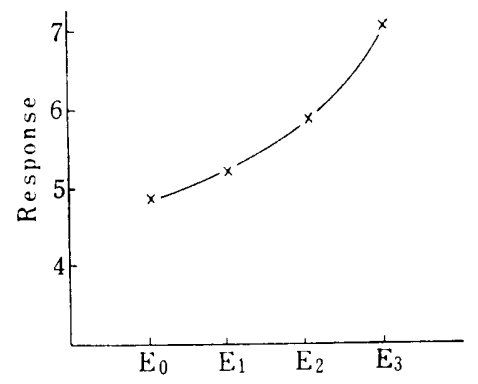

FIG. 2-6 Factor E

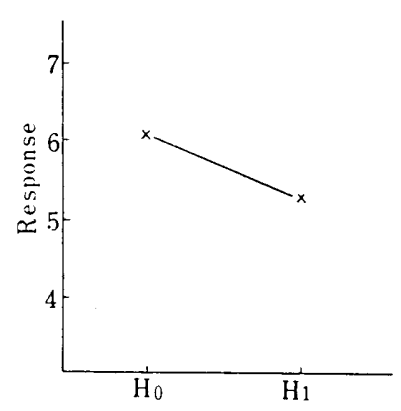

FIG. 2-8 Fator $\mathrm{H}$

(5) The main effects of factors $F$ and $H$ are represented in Fig. 2-7 and 2-8.

(6) The interaction between $F$ and $H$ is shown in Fig. 2-9, which gives that the effect of factor $H$ is negligibly small in " 0 " level of $F$.

\subsection{Simulations}

\subsubsection{Setting up of the models}

To visualize the efficiency of our inference in the RACOFFD experiments, we shall set up the synthetic models of experiments, as follows (refer to S. Brooks [8]).

As we have seen in our previous chapter of this paper, the objective world of our RACOFFD method can be assumed in the linear form of unknown parameters $\alpha_{1}^{\prime}, \alpha_{2}^{\prime}, \cdots, \alpha_{P}^{\prime}, \beta_{1}^{\prime}, \beta_{2}^{\prime}, \cdots, \beta_{R-1}^{\prime}$ and $\beta_{R}$ such that

$$
y_{n}=\sum_{p=1}^{P} \alpha_{p}^{\prime} x_{p n}+\sum_{r=1}^{R} \beta_{r}^{\prime} \xi_{r \pi(n)}+\dot{\varepsilon}_{n},
$$


where the variables $x_{p n}(p=1,2, \cdots, P ; n=1,2, \cdots, N)$ and $\xi_{r \pi(n)}(r=1,2$, $\cdots, R ; n=1,2, \cdots, N)$ are the elements of the design matrix

$$
D=\mid \begin{array}{lllr}
x_{11} & x_{12} & & x_{1 N} \\
\cdots & \cdots & \cdots & \cdots \\
\cdots & \cdots & \cdots & \cdots \\
x_{P 1} & x_{P 2} & \cdots & x_{P N} \\
\xi_{1 \pi(1)} & \xi_{1 \pi(2)} & \cdots & \xi_{1 \pi(N)} \\
\cdots & \cdots & \cdots & \cdots \\
\cdots & \cdots & \cdots & \cdots \\
\xi_{R \pi(1)} & \xi_{R \pi(2)} & \cdots & \xi_{R \pi(N)}
\end{array}
$$

If we control these variables in two levels having narrow interval, then a number of unknown parameters to be explored can be assumed to exist in our objective world, but the size of these parameters may be controlled under a small value. These aspects of experiments can be of ten found in the problem of quality control, where there are many unknown and uncontrolled factors which affect the variability of the qualities to be controlled.

As we have seen in chapter 1 of this paper, the power of test of the null hypothesis, $H_{0}: \alpha_{p}^{\prime}=0$, is affected by the size of three parameters $\alpha_{0}$, $\Phi=N-P$ and $\tau_{p}=N \alpha_{p}^{2} / 2\left(1+\mu_{2}\right)$, under the restricted situation which is determined by the parameters $N, \beta_{1}^{\prime}, \beta_{2}^{\prime}, \cdots, \beta_{R}^{\prime}$ refering to Table $1-2$.

Furthermore, the estimates in our RACOFFD situation are fluctuated according to the prescribed distribution under the restricted conditions.

\subsubsection{Designs and analysis}

Let us examine following three situations.

Model (A): We shall examine the power of test in the ordinary fractional factorial design such that $y_{n}=\sum_{p=1}^{P} \alpha_{p}^{\prime} x_{p n}+\varepsilon_{n}$, where $\left\{\alpha_{p}^{\prime}\right\}=\{1,0.5$, $0, \cdots \cdots, 0.5,1\}$ and $\left\{\dot{\varepsilon}_{n}\right\}=\{-0.6,2.1, \cdots,-1.5\}$ are randomly sampled from the rounded random numbers according to the normal distrbution with mean 0 and variance 1 . These synthetic data are tabulated in Table 2-5 with the design matrix, in which we shall denote the design matrix in the transposed style thus $\zeta_{n}=\sum_{p=1}^{P} \alpha_{p}^{\prime} x_{p n}$ in the 3 rd column from the last one $\varepsilon_{n}$ in the 2 nd column from the last and the synthetic responses in the last column.

The analysis of variance for these data is tabulated in Table 2-6, of which 1st column gives the symbols the 2nd column, the sum of squares corresponding to the items in the 1st column the succeeding columns give the same items as those of the ordinary analysis of variance table, except the last 2 columns which give the values of parameters. 
TABLE 2-5 Synthetic mndel of ordinary FFD

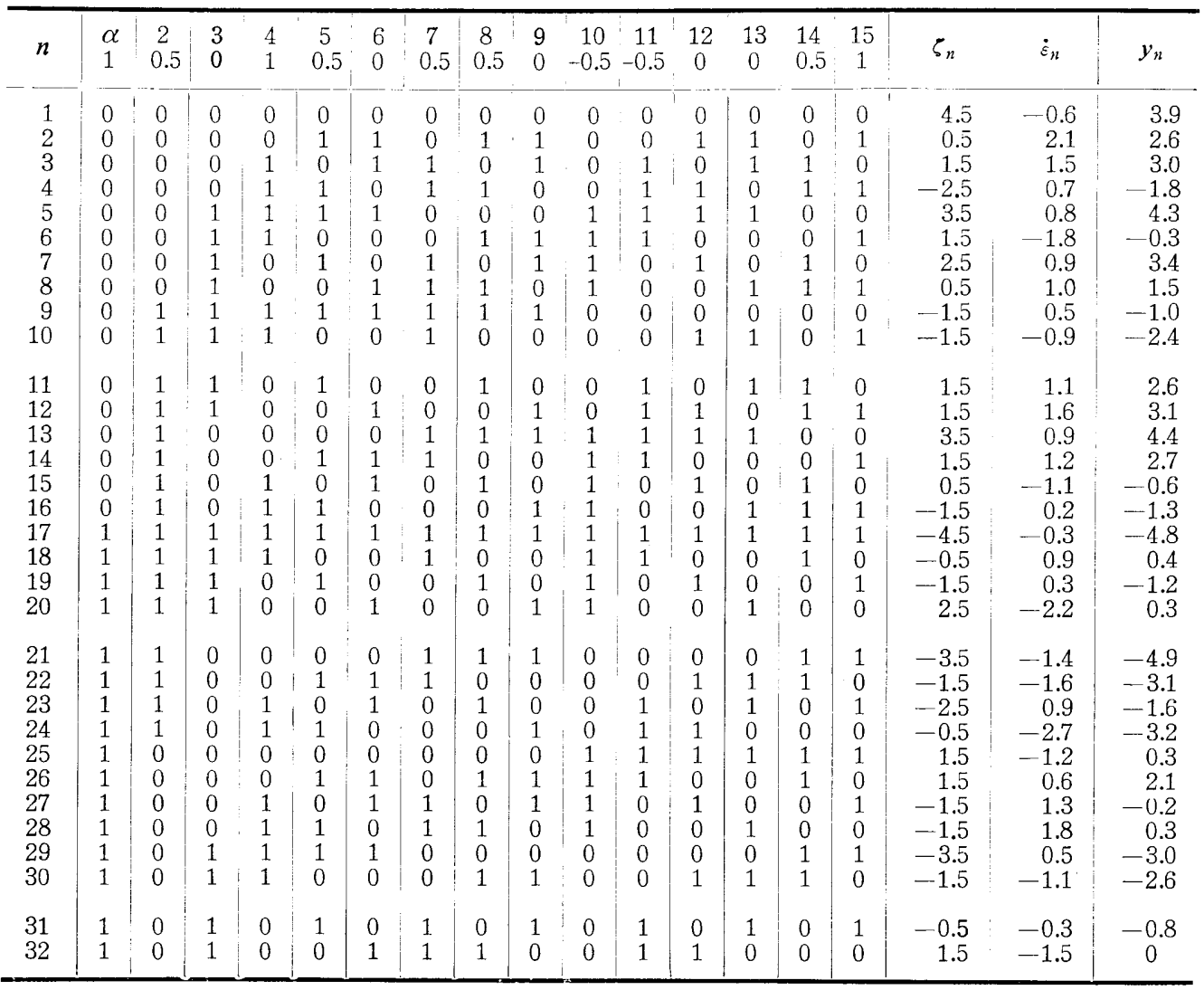

TABLE 2-6 Analysis of variance in FFD

\begin{tabular}{|c|c|c|c|c|c|c|}
\hline Parameters & S. S & D. F & M.S & $\mathrm{F}_{0}$ & Value of $\alpha_{p}$ & $\hat{\alpha}_{p}$ \\
\hline 1 & 66.41 & 1 & 66.41 & *33.71 & 1 & 1.44 \\
\hline 2 & 16.97 & 1 & 16.97 & * 8.61 & 0.5 & 0.73 \\
\hline 3 & 0.30 & 1 & 0.30 & 0.15 & 0 & 0.10 \\
\hline 4 & 31.40 & 1 & 31.40 & *15.94 & 1 & 0.99 \\
\hline 5 & 1.32 & 1 & 1.32 & 0.64 & 0.5 & 0.20 \\
\hline 6 & 2.26 & 1 & 2.26 & 1.15 & 0 & -0.26 \\
\hline 7 & 2.37 & 1 & 2.37 & 1.20 & 0.5 & 0.26 \\
\hline 8 & 5.04 & 1 & 5.04 & * 2.56 & 0.5 & 0.40 \\
\hline 9 & 0.20 & 1 & 0.20 & 0.10 & 0 & 0.10 \\
\hline 10 & 13.13 & 1 & 13.13 & * 6.66 & -0.5 & -0.64 \\
\hline 11 & 10.93 & 1 & 10.93 & * 5.55 & -0.5 & -0.58 \\
\hline 12 & 1.02 & 1 & 1.02 & 0.52 & 0 & 0.17 \\
\hline 13 & 0.34 & 1 & 0.34 & 0.17 & 0 & $-0,10$ \\
\hline 14 & 5.70 & 1 & 5.70 & * 2.89 & 0.5 & 0.41 \\
\hline 15 & 21.62 & 1 & 21.62 & $* 10.97$ & 1 & 0.82 \\
\hline $\begin{array}{l}\text { error } \\
\text { total }\end{array}$ & $\begin{array}{r}31.46 \\
210.47\end{array}$ & $\begin{array}{l}15 \\
32\end{array}$ & 1.97 & & $\sigma_{2}^{2}=$ & \\
\hline
\end{tabular}


Model (B): The second model is RACOFFD in which another fractional factorial design conbinates randomly to the model (A), such that $y_{n}$ $=\sum \alpha_{p}^{\prime} x_{p n}+\sum \beta_{r}^{\prime} \xi_{r \pi(n)}+\dot{\varepsilon}_{n}$, where $\left\{\alpha_{p}^{\prime}\right\}=\{1,0.5, \cdots, 0.5,1\},\left\{\beta_{r}^{\prime}\right\}=\{0,0.5, \cdots$, $0.5,0\},\left\{\dot{\varepsilon}_{n}\right\}=\{-0.6,2.1, \cdots,-0.3,-1.5\}$, are sampled from the normal population in the similar manner as in the model (A), and $\pi(n)$ is a permutation of the numbers $1,2, \cdots, 32$.

These synthetic data are tabulated in Table 2-7 with the RACOFFD design matrix in which the design matrix is presented in the transposed style as in the model (A), the 1st sub-matrix is presented in the columns from 2 nd to 16 th, 2nd sub-matrix $\xi_{r \pi(n)}(r=1,2, \cdots, R ; n=1,2, \cdots, 32)$ is presented in the columns from 18th to 33 th, and $\zeta_{n}=\sum_{p=1}^{P} \alpha_{p} x_{p n}, v_{\pi(n)}=$ $\sum_{r=1}^{R} \beta_{r}^{\prime} \xi_{r \pi(n)}$ are presented in the 17 th and 34 th columns, respectively, and so on.

The analysis of variances of these data concerning to the 1st group factors $\left\{\alpha_{p}^{\prime}\right\}(p=1,2, \cdots, P)$ is given in Table $2-8$ and similar one for the 2nd group of factors $\left\{\beta_{r}^{\prime}\right\} \quad(r=1,2, \cdots, R)$ is given in Table 2-9.

Model (C) : The last model is the RACOFFD design in which we shall confirm the efficiency of our inference in the results of model (B). Then, we have the model $y_{n}=\sum \alpha_{p}^{\prime} x_{p n}+\sum \beta_{r}^{\prime} \xi_{r \pi(n)}+\dot{\varepsilon}_{n}$, where $\left\{\alpha_{p}^{\prime}\right\}=-0.5$, $1, \cdots, 0.5,-0.5,\left\{\beta_{r}^{\prime}\right\}=0,0, \cdots,-0.5,\left\{\dot{\varepsilon}_{n}\right\}=-0.8,0.4, \cdots,-1.2$, are constructed in similar way to the previous model, and $\pi(n)$ is also a permutation of 32 numbers. These synthetic data with design matrix are presented in Table 2-10 as tabulated in similar way to Table 2-7, and the results of analysis of variance concerning to 1 st and 2 nd group factors are given in Table 2-11 and 2-12, respectively.

\subsubsection{Considerations on the results of the simulations}

In these synthetic experiments, we can observe the fact that the parameters having large value, 1 or -1 , are detected by these RACOFFD method same as the results in the ordinary fractional factorial designs, and the parameters having small value which is 0.5 or -0.5 , are not always detected by these RACOFFD same as the results in the ordinary fractional factorial designs. In the contrary, the non-significant parameters are sometimes judged significant in the RACOFFD test, in which we tested the null hypothesis $H_{0}: \alpha_{p}^{\prime}=0$ by appealing to the statistic $F$ in the size of test $\alpha_{0}=0.20$.

In virtue of the results in chapter 1, we can evaluate the of power of test by

$$
1-Q_{2}=1-I_{x_{0}}\left(\frac{\nu_{p}}{2}, \frac{\Phi}{2}\right)
$$


TABLE 2-7 Synthetic

(1)

\begin{tabular}{|c|c|c|c|c|c|c|c|c|c|c|c|c|c|c|c|c|c|}
\hline$n$ & $\begin{array}{c}\alpha \\
1\end{array}$ & $\begin{array}{c}2 \\
0.5\end{array}$ & $\begin{array}{l}3 \\
0\end{array}$ & $\begin{array}{l}4 \\
1\end{array}$ & $\begin{array}{c}5 \\
0.5\end{array}$ & $\begin{array}{l}6 \\
0\end{array}$ & $\begin{array}{c}7 \\
0.5\end{array}$ & $\begin{array}{c}8 \\
0.5\end{array}$ & $\begin{array}{l}9 \\
0\end{array}$ & $\begin{array}{r}10 \\
-0.5\end{array}$ & $\begin{array}{c}11 \\
-0.5\end{array}$ & $\begin{array}{c}12 \\
0\end{array}$ & $\begin{array}{c}13 \\
0\end{array}$ & $\begin{array}{l}14 \\
0.5\end{array}$ & $\begin{array}{c}15 \\
1\end{array}$ & $\varsigma_{n}$ & $\pi(n)$ \\
\hline 1 & 0 & 0 & 0 & 0 & 0 & 0 & 0 & 0 & 0 & 0 & 0 & 0 & 0 & 0 & 0 & 4.5 & 23 \\
\hline 2 & 0 & 0 & 0 & 0 & 1 & 1 & 0 & 1 & 1 & 0 & 0 & 1 & 1 & 0 & 1 & 0.5 & 29 \\
\hline 3 & 0 & 0 & 0 & 1 & 0 & 1 & 1 & 0 & 1 & 0 & 1 & 0 & 1 & 1 & 0 & 1.5 & 16 \\
\hline 4 & 0 & 0 & 0 & 1 & 1 & 0 & 1 & 1 & 0 & 0 & 1 & 1 & 0 & 1 & 1 & --2.5 & 32 \\
\hline 5 & 0 & 0 & 1 & 1 & 1 & 1 & 0 & 0 & 0 & 1 & 1 & 1 & 1 & 0 & 0 & 3.5 & 24 \\
\hline 6 & 0 & 0 & 1. & 1 & 0 & 0 & 0 & 1 & 1 & 1 & 1 & 0 & 0 & 0 & 1 & 1.5 & 26 \\
\hline 7 & 0 & 0 & 1 & 0 & 1 & 0 & 1 & 0 & 1 & 1 & 0 & 1 & 0 & 1 & 0 & 2.5 & 18 \\
\hline 8 & 0 & 0 & 1 & 0 & 0 & 1 & 1 & 1 & 0 & 1 & 0 & 0 & 1 & 1. & 1 & 0.5 & 27 \\
\hline 9 & 0 & 1 & 1 & 1 & 1 & 1 & 1 & 1 & 1 & 0 & 0 & 0 & 0 & 0 & 0 & -1.5 & 13 \\
\hline 10 & 0 & 1 & 1 & 1 & 0 & 0 & 1 & 0 & 0 & 0 & 0 & 1 & 1 & 0 & 1 & -1.5 & 5 \\
\hline 11 & 0 & 1 & 1 & 0 & 1 & 0 & 0 & 1 & 0 & 0 & 1 & 0 & 1 & 1 & 0 & 1.5 & 6 \\
\hline 12 & 0 & 1 & 1 & 0 & 0 & 1. & 0 & 0 & 1 & 0 & 1 & 1 & 0 & 1 & 1 & 1.5 & 15 \\
\hline 13 & 0 & 1. & 0 & 0 & 0 & 0 & 1 & 1 & 1 & 1 & 1 & 1 & 1 & 0 & 0 & 3.5 & 10 \\
\hline 14 & 0 & 1 & 0 & 0 & I & 1 & 1 & 0 & 0 & 1 & 1 & 0 & 0 & 0 & 1 & 1.5 & 25 \\
\hline 15 & 0 & 1 & 0 & 1 & 0 & 1 & 0 & 1 & 0 & 1 & 0 & 1 & 0 & 1 & 0 & 0.5 & 1 \\
\hline 16 & 0 & 1 & 0 & 1 & 1 & 0 & 0 & 0 & 1 & 1 & 0 & 0 & 1 & 1. & 1 & -1.5 & 7 \\
\hline 17 & 1 & 1 & 1 & 1 & 1 & 1 & 1 & 1 & 1 & 1 & 1 & 1 & 1 & 1 & 1 & -4.5 & 3 \\
\hline 18 & 1 & 1 & 1 & 1 & 0 & 0 & 1 & 0 & 0 & 1 & 1 & 0 & 0 & 1 & 0 & -0.5 & 28 \\
\hline 19 & 1 & 1 & 1 & 0 & 1 & 0 & 0 & 1 & 0 & 1 & 0 & 1 & 0 & 0 & 1 & -1.5 & 14 \\
\hline 20 & 1 & 1 & 1 & 0 & 0 & 1 & 0 & 0 & 1 & 1 & 0 & 0 & 1 & 0 & 0 & 2.5 & 30 \\
\hline 21 & 1 & 1 & 0 & 0 & 0 & 0 & 1 & 1 & 1 & 0 & 0 & 0 & 0 & 1 & 1 & -3.5 & 8 \\
\hline 22 & 1 & 1 & 0 & 0 & 1 & 1 & 1 & 0 & 0 & 0 & 0 & 1 & 1 & 1 & 0 & -1.5 & 22 \\
\hline 23 & 1 & 1 & 0 & 1 & 0 & 1 & 0 & 1 & 0 & 0 & 1 & 0 & 1 & 0 & 1 & -2.5 & 20 \\
\hline 24 & 1 & 1 & 0 & 1 & 1 & 0 & 0 & 0 & 1. & 0 & 1 & 1 & 0 & 0 & 0 & -0.5 & 31 \\
\hline 25 & 1 & 0 & 0 & 0 & 0 & 0 & 0 & 0 & 0 & 1 & 1 & 1 & 1 & 1 & 1 & 1.5 & 11 \\
\hline 26 & 1 & 0 & 0 & 0 & 1 & 1 & 0 & 1 & 1 & 1 & 1 & 0 & 0 & 1 & 0 & 1.5 & 9 \\
\hline 27 & 1 & 0 & 0 & 1 & 0 & 1 & 1 & 0 & 1 & 1 & 0 & 1 & 0 & 0 & 1 & -1.5 & 2 \\
\hline 28 & 1 & 0 & 0 & 1 & 1 & 0 & 1 & 1 & 0 & 1 & 0 & 0 & 1 & 0 & 0 & -1.5 & 21 \\
\hline 29 & 1 & 0 & 1 & 1 & 1 & 1 & 0 & 0 & 0 & 0 & 0 & 0 & 0 & 1 & 1 & -3.5 & 4 \\
\hline 30 & 1 & 0 & 1 & 1 & 0 & 0 & 0 & 1 & 1 & 0 & 0 & 1 & 1 & 1 & 0 & -1.5 & 12 \\
\hline 31 & 1 & 0 & 1 & 0 & 1 & 0 & 1 & 0 & 1. & 0 & 1 & 0 & 1 & 0 & 1 & -0.5 & 19 \\
\hline 32 & 1 & 0 & 1 & 0 & 0 & 1 & 1 & 1 & 0 & 0 & 1 & 1 & 0 & 0 & 0 & 1.5 & 17 \\
\hline
\end{tabular}

TABLE 2-8 Analysis of variance in RACOFFD

1st gronp

\begin{tabular}{|c|c|c|c|c|c|c|}
\hline Parameters & S. S & D. F & M.S & $\mathrm{F}_{0}$ & Value of $\alpha_{p}$ & $\hat{\alpha}_{p}$ \\
\hline $\begin{array}{r}1 \\
2 \\
3 \\
4 \\
5 \\
6 \\
7 \\
8 \\
9 \\
10 \\
11 \\
12 \\
13 \\
14 \\
15\end{array}$ & $\begin{array}{r}75.34 \\
36.77 \\
1.16 \\
13.39 \\
6.57 \\
0.63 \\
20.64 \\
7.70 \\
0.38 \\
20.32 \\
5.87 \\
0.02 \\
1.24 \\
6.57 \\
14.18\end{array}$ & $\begin{array}{l}1 \\
1 \\
1 \\
1 \\
1 \\
1 \\
1 \\
1 \\
1 \\
1 \\
1 \\
1 \\
1 \\
1 \\
1\end{array}$ & $\begin{array}{r}75.34 \\
36.77 \\
1.16 \\
13.39 \\
6.57 \\
0.63 \\
20.64 \\
7.70 \\
0.38 \\
20.38 \\
5.87 \\
0.02 \\
1.24 \\
6.57 \\
14.18\end{array}$ & $\begin{array}{l}* 17.20 \\
* 8.38 \\
0.26 \\
* 3.06 \\
1.50 \\
0.14 \\
* 4.71 \\
1.76 \\
0.09 \\
* 4.64 \\
1.34 \\
0 \\
0.28 \\
1.50 \\
* 3.24\end{array}$ & $\begin{array}{l}1 \\
0.5 \\
0 \\
1 \\
0.5 \\
0 \\
0.5 \\
0.5 \\
0 \\
-0.5 \\
-0.5 \\
0 \\
0 \\
0.5 \\
1\end{array}$ & $\begin{array}{r}1.54 \\
1.07 \\
0.19 \\
0.65 \\
-0.45 \\
0.14 \\
0.80 \\
0.49 \\
0.11 \\
-0.80 \\
-0.43 \\
0.02 \\
-0.20 \\
0.45 \\
0.67\end{array}$ \\
\hline $\begin{array}{l}\text { error } \\
\text { total }\end{array}$ & $\begin{array}{r}70.13 \\
280.91\end{array}$ & $\begin{array}{l}15 \\
32\end{array}$ & 4.38 & \multicolumn{3}{|c|}{$\sigma_{1}^{2}+\sigma_{2}^{2}=3.67$} \\
\hline
\end{tabular}


model in RACOFFD

(2)

\begin{tabular}{|c|c|c|c|c|c|c|c|c|c|c|c|c|c|c|c|c|c|}
\hline $\begin{array}{l}\beta 1 \\
0\end{array}$ & $\begin{array}{c}2 \\
0.5\end{array}$ & $\begin{array}{c}3 \\
-0.5\end{array}$ & $\begin{array}{c}4 \\
0.5\end{array}$ & $\begin{array}{c}5 \\
-0.5\end{array}$ & $\begin{array}{c}6 \\
0.5\end{array}$ & $\begin{array}{l}7 \\
0\end{array}$ & $\begin{array}{l}8 \\
0\end{array}$ & $\begin{array}{l}9 \\
0\end{array}$ & $\begin{array}{l}10 \\
0.5\end{array}$ & $\begin{array}{c}11 \\
0\end{array}$ & $\begin{array}{c}12 \\
-0.5\end{array}$ & $\begin{array}{c}13 \\
1\end{array}$ & $\begin{array}{l}14 \\
0.5\end{array}$ & $\begin{array}{c}15 \\
0\end{array}$ & $v_{n}$ & $\varepsilon_{n}$ & $y_{u}$ \\
\hline $\begin{array}{l}1 \\
1 \\
0 \\
1 \\
1 \\
1 \\
1 \\
1 \\
1 \\
0 \\
0\end{array}$ & $\begin{array}{l}1 \\
0 \\
1 \\
0 \\
1 \\
0 \\
1 \\
0 \\
1 \\
0\end{array}$ & $\begin{array}{l}0 \\
1 \\
0 \\
1 \\
0 \\
0 \\
1 \\
0 \\
0 \\
1\end{array}$ & $\begin{array}{l}1 \\
1 \\
1 \\
0 \\
1 \\
0 \\
1 \\
1 \\
0 \\
1\end{array}$ & $\begin{array}{l}0 \\
1 \\
1 \\
0 \\
1 \\
1 \\
0 \\
0 \\
0 \\
1\end{array}$ & $\begin{array}{l}1 \\
1 \\
0 \\
1 \\
0 \\
1 \\
0 \\
1 \\
0 \\
1\end{array}$ & $\begin{array}{l}0 \\
0 \\
0 \\
1 \\
0 \\
0 \\
1 \\
1 \\
1 \\
0\end{array}$ & $\begin{array}{l}1 \\
0 \\
0 \\
1 \\
0 \\
1 \\
0 \\
0 \\
1 \\
0\end{array}$ & $\begin{array}{l}0 \\
0 \\
1 \\
0 \\
1 \\
1 \\
0 \\
1 \\
1 \\
0\end{array}$ & $\begin{array}{l}0 \\
0 \\
1 \\
0 \\
0 \\
1 \\
1 \\
1 \\
1 \\
1\end{array}$ & $\begin{array}{l}1 \\
0 \\
0 \\
1 \\
1 \\
1 \\
1 \\
0 \\
1 \\
1\end{array}$ & $\begin{array}{l}0 \\
0 \\
0 \\
1 \\
1 \\
0 \\
0 \\
1 \\
1 \\
1\end{array}$ & $\begin{array}{l}1 \\
0 \\
1 \\
0 \\
0 \\
0 \\
0 \\
0 \\
1 \\
1\end{array}$ & $\begin{array}{l}0 \\
1 \\
1 \\
0 \\
0 \\
1 \\
1 \\
0 \\
0 \\
0\end{array}$ & $\begin{array}{l}1 \\
1 \\
1 \\
0 \\
0 \\
0 \\
0 \\
1 \\
0 \\
0\end{array}$ & $\begin{array}{c}-2.0 \\
1.0 \\
-3.0 \\
3.0 \\
2.0 \\
0 \\
-1.0 \\
0 \\
-1.0 \\
0\end{array}$ & $\begin{array}{r}-0.6 \\
2.1 \\
1.5 \\
0.7 \\
0.8 \\
-1.8 \\
0.9 \\
1.0 \\
0.5 \\
-0.9\end{array}$ & $\begin{array}{r}1.9 \\
3.6 \\
0 \\
1.2 \\
6.3 \\
-0.3 \\
2.4 \\
1.5 \\
-2.0 \\
-2.4\end{array}$ \\
\hline $\begin{array}{l}0 \\
0 \\
0 \\
1 \\
0 \\
0 \\
0 \\
1 \\
0 \\
1\end{array}$ & $\begin{array}{l}0 \\
1 \\
1 \\
0 \\
0 \\
0 \\
0 \\
0 \\
1 \\
0\end{array}$ & $\begin{array}{l}1 \\
0 \\
1 \\
0 \\
0 \\
1 \\
0 \\
0 \\
0 \\
1\end{array}$ & $\begin{array}{l}1 \\
1 \\
1 \\
0 \\
0 \\
0 \\
1 \\
1 \\
0 \\
1\end{array}$ & $\begin{array}{l}0 \\
0 \\
0 \\
0 \\
0 \\
1 \\
0 \\
1 \\
1 \\
0\end{array}$ & $\begin{array}{l}0 \\
1 \\
0 \\
0 \\
0 \\
0 \\
1 \\
0 \\
1 \\
0\end{array}$ & $\begin{array}{l}0 \\
0 \\
1 \\
0 \\
0 \\
1 \\
1 \\
1 \\
1 \\
0\end{array}$ & $\begin{array}{l}1 \\
1 \\
0 \\
0 \\
0 \\
0 \\
0 \\
1 \\
0 \\
1\end{array}$ & $\begin{array}{l}1 \\
0 \\
0 \\
0 \\
0 \\
1 \\
1 \\
0 \\
0 \\
1\end{array}$ & $\begin{array}{l}1 \\
1 \\
0 \\
1 \\
0 \\
1 \\
0 \\
1 \\
1 \\
0\end{array}$ & $\begin{array}{l}1 \\
0 \\
0 \\
1 \\
0 \\
0 \\
1 \\
0 \\
1 \\
0\end{array}$ & $\begin{array}{l}0 \\
1 \\
1 \\
1 \\
0 \\
1 \\
0 \\
0 \\
0 \\
1\end{array}$ & $\begin{array}{l}0 \\
0 \\
1 \\
1 \\
0 \\
0 \\
1 \\
1 \\
0 \\
1\end{array}$ & $\begin{array}{l}0 \\
1 \\
0 \\
1 \\
0 \\
1 \\
1 \\
0 \\
0 \\
1\end{array}$ & $\begin{array}{l}1 \\
0 \\
1 \\
1 \\
0 \\
0 \\
0 \\
0 \\
1 \\
0\end{array}$ & $\begin{array}{c}1.0 \\
-2.0 \\
0 \\
-1.0 \\
2.0 \\
3.0 \\
-3.0 \\
-1.0 \\
0 \\
0\end{array}$ & $\begin{array}{r}1.1 \\
1.6 \\
0.9 \\
1.2 \\
-1.1 \\
0.2 \\
-0.3 \\
0.9 \\
0.3 \\
-2.2\end{array}$ & $\begin{array}{r}3.6 \\
1.1 \\
4.4 \\
1.7 \\
1.4 \\
1.7 \\
-7.8 \\
-0.6 \\
-1.2 \\
-0.3\end{array}$ \\
\hline $\begin{array}{l}0 \\
1 \\
1 \\
1 \\
0 \\
0 \\
0 \\
1 \\
0 \\
0\end{array}$ & $\begin{array}{l}0 \\
1 \\
1 \\
0 \\
1 \\
1 \\
0 \\
1 \\
0 \\
1\end{array}$ & $\begin{array}{l}1 \\
0 \\
1 \\
1 \\
1 \\
1 \\
0 \\
0 \\
0 \\
1\end{array}$ & $\begin{array}{l}0 \\
0 \\
0 \\
0 \\
0 \\
1 \\
0 \\
0 \\
1 \\
0\end{array}$ & $\begin{array}{l}0 \\
1 \\
0 \\
1 \\
1 \\
1 \\
1 \\
0 \\
1 \\
0\end{array}$ & $\begin{array}{l}1 \\
1 \\
1 \\
0 \\
0 \\
1 \\
1 \\
0 \\
0 \\
1\end{array}$ & $\begin{array}{l}1 \\
1 \\
0 \\
1 \\
0 \\
1 \\
0 \\
1 \\
1 \\
0\end{array}$ & $\begin{array}{l}1 \\
0 \\
0 \\
0 \\
1 \\
1 \\
1 \\
1 \\
1 \\
0\end{array}$ & $\begin{array}{l}0 \\
0 \\
1 \\
1 \\
0 \\
1 \\
1 \\
1 \\
0 \\
1\end{array}$ & $\begin{array}{l}1 \\
0 \\
1 \\
0 \\
0 \\
0 \\
0 \\
0 \\
0 \\
0\end{array}$ & $\begin{array}{l}0 \\
0 \\
0 \\
1 \\
1 \\
0 \\
0 \\
0 \\
1 \\
1\end{array}$ & $\begin{array}{l}0 \\
1 \\
0 \\
0 \\
0 \\
0 \\
1 \\
0 \\
1 \\
1\end{array}$ & $\begin{array}{l}1 \\
1 \\
1 \\
1 \\
1 \\
0 \\
1 \\
0 \\
0 \\
0\end{array}$ & $\begin{array}{l}1 \\
1 \\
0 \\
0 \\
1 \\
0 \\
0 \\
1 \\
1 \\
1\end{array}$ & $\begin{array}{l}1 \\
0 \\
0 \\
1 \\
0 \\
0 \\
1 \\
1 \\
1 \\
1\end{array}$ & $\begin{array}{c}-2.0 \\
-1.0 \\
-2.0 \\
2.0 \\
0 \\
1.0 \\
1.0 \\
0 \\
2.0 \\
1.0\end{array}$ & $\begin{array}{r}-1.4 \\
-1.6 \\
0.9 \\
-2.7 \\
-1.2 \\
0.6 \\
1.3 \\
1.8 \\
0.5 \\
-1.1\end{array}$ & $\begin{array}{r}-6.9 \\
-4.1 \\
-3.6 \\
-1.2 \\
0.3 \\
3.1 \\
0.8 \\
0.3 \\
-1.0 \\
-1.6\end{array}$ \\
\hline $\begin{array}{l}1 \\
1\end{array}$ & $\begin{array}{l}1 \\
1\end{array}$ & $\begin{array}{l}1 \\
1\end{array}$ & $\begin{array}{l}0 \\
1\end{array}$ & $\begin{array}{l}1 \\
1\end{array}$ & $\begin{array}{l}0 \\
1\end{array}$ & $\begin{array}{l}0 \\
1\end{array}$ & $\begin{array}{l}1 \\
1\end{array}$ & $\begin{array}{l}0 \\
1\end{array}$ & $\begin{array}{l}1 \\
1\end{array}$ & $\begin{array}{l}0 \\
1\end{array}$ & $\begin{array}{l}1 \\
1\end{array}$ & $\begin{array}{l}0 \\
1\end{array}$ & $\begin{array}{l}0 \\
1\end{array}$ & $\begin{array}{l}1 \\
1\end{array}$ & $\begin{array}{r}3.0 \\
-2.0\end{array}$ & $\begin{array}{l}-0.3 \\
-1.5\end{array}$ & $\begin{array}{r}2.2 \\
-2.0\end{array}$ \\
\hline
\end{tabular}

TABLE 2-9 Analysis of variance in RACOFFD

2nd group

\begin{tabular}{|c|c|c|c|c|c|c|}
\hline Parameters & S.S & D. F & M. S & $\mathrm{F}_{0}$ & Value of $\beta_{r}$ & $\hat{\beta}_{\boldsymbol{r}}$ \\
\hline $\begin{array}{r}1 \\
2 \\
3 \\
4 \\
5 \\
6 \\
7 \\
8 \\
9 \\
9 \\
10 \\
11 \\
12 \\
13 \\
14 \\
15\end{array}$ & $\begin{array}{r}8.10 \\
4.43 \\
1.58 \\
20.64 \\
1.67 \\
41.63 \\
23.63 \\
0.03 \\
0.75 \\
5.04 \\
1.57 \\
5.36 \\
64.70 \\
23.98 \\
2.59\end{array}$ & $\begin{array}{l}1 \\
1 \\
1 \\
1 \\
1 \\
1 \\
1 \\
1 \\
1 \\
1 \\
1 \\
1 \\
1 \\
1 \\
1\end{array}$ & $\begin{array}{r}8.10 \\
4.43 \\
1.58 \\
20.64 \\
1.67 \\
41.63 \\
23.63 \\
0.03 \\
0.04 \\
5.04 \\
1.67 \\
5.36 \\
64.70 \\
23.98 \\
2.59\end{array}$ & $\begin{array}{r}1.73 \\
0.94 \\
0.34 \\
* 4.40 \\
0.36 \\
* \quad 8.88 \\
* 5.04 \\
0.01 \\
0.16 \\
1.07 \\
0.36 \\
1.14 \\
* 13.80 \\
* 5.11 \\
0.55\end{array}$ & $\begin{array}{l}0 \\
0.5 \\
-0.5 \\
0.5 \\
-0.5 \\
0.5 \\
0 \\
0 \\
0 \\
0.5 \\
0 \\
-0.5 \\
1 \\
0.5 \\
0\end{array}$ & $\begin{array}{r}-0.50 \\
-0.37 \\
-0.22 \\
-0.80 \\
-0.23 \\
1.14 \\
0.86 \\
-0.03 \\
0.15 \\
0.40 \\
0.23 \\
-0.41 \\
1.42 \\
0.87 \\
-0.28\end{array}$ \\
\hline $\begin{array}{l}\text { error } \\
\text { total }\end{array}$ & $\begin{array}{r}75.11 \\
280.91\end{array}$ & $\begin{array}{l}15 \\
32\end{array}$ & 4.69 & \multicolumn{3}{|c|}{$\sigma_{1}^{2}+\sigma_{2}^{2}=5.75$} \\
\hline
\end{tabular}


TABLE 2-10 Synthetic

\begin{tabular}{|c|c|c|c|c|c|c|c|c|c|c|c|c|c|c|c|c|c|}
\hline$n$ & $\begin{array}{c}\alpha 1 \\
-0.5\end{array}$ & $\begin{array}{l}2 \\
1\end{array}$ & $\begin{array}{c}3 \\
-0.5\end{array}$ & $\begin{array}{c}4 \\
-0.5\end{array}$ & $\begin{array}{c}5 \\
0.5\end{array}$ & $\begin{array}{l}6 \\
0\end{array}$ & $\begin{array}{c}7 \\
-0.5\end{array}$ & $\begin{array}{l}8 \\
0\end{array}$ & $\begin{array}{c}9 \\
0.5\end{array}$ & $\begin{array}{c}10 \\
1\end{array}$ & $\begin{array}{l}11 \\
0.5\end{array}$ & $\begin{array}{c}12 \\
-0.5\end{array}$ & $\begin{array}{c}13 \\
1\end{array}$ & $\begin{array}{l}14 \\
0.5\end{array}$ & $\begin{array}{c}15 \\
-0.5\end{array}$ & $\zeta_{n}$ & $\pi(n)$ \\
\hline 1 & 0 & 0 & 0 & 0 & 0 & 0 & 0 & 0 & 0 & 0 & 0 & 0 & 0 & 0 & 0 & 2.0 & 15 \\
\hline 2 & 0 & 0 & 0 & 0 & 1 & 1 & 0 & 1 & 1. & 0 & 0 & 1 & 1 & 0 & 1 & 0 & 19 \\
\hline 3 & 0 & 0 & 0 & 1 & 0 & 1 & 1 & 0 & 1 & 0 & 1 & 0 & 1 & 1 & 0 & -1.0 & 3 \\
\hline 4 & 0 & 0 & 0 & 1 & 1 & 0 & 1 & 1 & 0 & 0 & 1 & 1 & 0 & 1 & 1 & 3.0 & 4 \\
\hline 5 & 0 & 0 & 1 & 1 & 1 & 1 & 0 & 0 & 0 & 1 & 1 & 1 & 1 & 0 & 0 & -1.0 & 7 \\
\hline 6 & 0 & 0 & 1 & 1 & 0 & 0 & 0 & 1 & 1 & 1 & 1 & 0 & 0 & 0 & 1 & 1.0 & 22 \\
\hline 7 & 0 & 0 & 1 & 0 & 1 & 0 & 1 & 0 & 1 & 1 & 0 & 1 & 0 & 1 & 0 & 0 & 32 \\
\hline 8 & 0 & 0 & 1 & 0 & 0 & 1 & 1 & 1 & 0 & 1 & 0 & 0 & 1 & 1 & 1 & 0 & 28 \\
\hline 9 & 0 & 1. & 1 & 1 & 1 & 1 & 1 & 1 & 1. & 0 & 0 & 0 & 0 & 0 & 0 & 1.0 & 9 \\
\hline 10 & 0 & 1 & 1. & 1 & 0 & 0 & 1 & 0 & 0 & 0 & 0 & 1 & 1 & 0 & 1 & 3.0 & 14 \\
\hline 11 & 0 & 1 & 1 & 0 & 1 & 0 & 0 & 1 & 0 & 0 & 1 & 0 & 1 & 1 & 0 & -4.0 & 18 \\
\hline 12 & 0 & 1 & 1 & 0 & 0 & 1 & 0 & 0 & 1 & 0 & 1 & 1 & 0 & 1 & 1 & 0 & 16 \\
\hline 13 & 0 & 1 & 0 & 0 & 0 & 0 & 1 & 1 & 1 & 1 & 1 & 1 & 1 & 0 & 0 & -4.0 & 1 \\
\hline 14 & 0 & 1 & 0 & 0 & 1 & 1 & 1 & 0 & 0 & 1 & 1 & 0 & 0 & 0 & 1 & -2.0 & 5 \\
\hline 15 & 0 & 1 & 0 & 1 & 0 & 1 & 0 & 1 & 0 & 1 & 0 & 1 & 0 & 1 & 0 & -1.0 & 29 \\
\hline 16 & 0 & 1 & 0 & 1 & 1 & 0 & 0 & 0 & 1 & 1 & 0 & 0 & 1 & 1 & 1 & -5.0 & 12 \\
\hline 17 & 1 & 1 & 1 & 1 & 1 & 1 & 1 & 1 & 1 & 1 & 1 & 1 & 1 & 1 & 1 & -2.0 & 25 \\
\hline 18 & 1 & 1 & 1 & 1 & 0 & 0 & 1 & 0 & 0 & 1 & 1 & 0 & 0 & 1 & 0 & 0 & 20 \\
\hline 19 & 1 & 1 & 1 & 0 & 1 & 0 & 0 & 1 & 0 & 1 & 0 & 1 & 0 & 0 & 1 & 1.0 & 26 \\
\hline 20 & 1 & 1 & 1 & 0 & 0 & 1 & 0 & 0 & 1 & 1 & 0 & 0 & 1 & 0 & 0 & -3.0 & 17 \\
\hline 21 & 1 & 1 & 0 & 0 & 0 & 0 & 1 & 1 & 1 & 0 & 0 & 0 & 0 & 1 & 1 & 1.0 & 24 \\
\hline 22 & 1 & 1 & 0 & 0 & 1 & 1 & 1 & 0 & 0 & 0 & 0 & 1 & 1 & 1 & 0 & -1.0 & 13 \\
\hline 23 & 1 & 1 & 0 & 1 & 0 & 1 & 0 & 1 & 0 & 0 & 1 & 0 & 1 & 0 & 1 & 0 & 31 \\
\hline 24 & 1 & 1 & 0 & 1 & 1 & 0 & 0 & 0 & 1 & 0 & 1 & 1 & 0 & 0 & 0 & 0 & 2 \\
\hline 25 & 1 & 0 & 0 & 0 & 0 & 0 & 0 & 0 & 0 & 1 & 1 & 1 & 1 & 1 & 1 & -1.0 & 8 \\
\hline 26 & 1 & 0 & 0 & 0 & 1 & 1 & 0 & 1 & 1 & 1 & 1. & 0 & 0 & 1 & 0 & -3.0 & 21 \\
\hline 27 & 1 & 0 & 0 & 1 & 0 & 1 & 1 & 0 & 1 & 1 & 0 & 1 & 0 & 0 & 1 & 4.0 & 30 \\
\hline 28 & 1 & 0 & 0 & 1 & 1 & 0 & 1 & 1 & 0 & 1 & 0 & 0 & 1 & 0 & 0 & 0 & 6 \\
\hline 29 & 1 & 0 & 1 & 1 & 1 & 1 & 0 & 0 & 0 & 0 & 0 & 0 & 0 & 1 & 1 & 4.0 & 27 \\
\hline 30 & 1 & 0 & 1 & 1 & 0 & 0 & 0 & 1 & 1 & 0 & 0 & 1 & 1 & 1 & 0 & 2.0 & 10 \\
\hline 31 & 1 & 0 & 1 & 0 & 1 & 0 & 1 & 0 & 1 & 0 & 1 & 0 & 1 & 0 & 1 & 1.0 & 11 \\
\hline 32 & 1 & 0 & 1 & 0 & 0 & 1 & 1 & 1 & 0 & 0 & 1 & 1 & 0 & 0 & 0 & 5.0 & 23 \\
\hline
\end{tabular}

TABLE 2-11 Analysis of variance in RACOFFD

1st group

\begin{tabular}{|c|c|c|c|c|c|c|}
\hline Parameters & S. S & D. F & M.S & $\mathrm{F}_{0}$ & Value of $\alpha_{p}$ & $\bar{\alpha}_{p}$ \\
\hline $\begin{array}{r}1 \\
2 \\
3 \\
4 \\
5 \\
6 \\
7 \\
8 \\
9 \\
10 \\
11 \\
12 \\
13 \\
14 \\
15\end{array}$ & $\begin{array}{r}4.43 \\
14.18 \\
21.29 \\
30.23 \\
0.69 \\
1.49 \\
14.45 \\
16.39 \\
0.95 \\
17.26 \\
28.31 \\
36.34 \\
22.61 \\
2.82 \\
16.10\end{array}$ & $\begin{array}{l}1 \\
1 \\
1 \\
1 \\
1 \\
1 \\
1 \\
1 \\
1 \\
1 \\
1 \\
1 \\
1 \\
1 \\
1\end{array}$ & $\begin{array}{r}4.43 \\
14.18 \\
21.29 \\
30.23 \\
0.69 \\
1.49 \\
14.45 \\
16.39 \\
0.95 \\
17.26 \\
28.31 \\
36.34 \\
22.61 \\
2.82 \\
16.10\end{array}$ & $\begin{array}{r}1.21 \\
* 3.83 \\
* 5.80 \\
* 8.24 \\
0.19 \\
0.41 \\
* 3.94 \\
* 4.47 \\
0.26 \\
* 4.70 \\
* 7.71 \\
* 9.90 \\
* 6.16 \\
0.77 \\
* 4.39\end{array}$ & $\begin{array}{c}-0.5 \\
1 \\
-0.5 \\
-0.5 \\
0.5 \\
0 \\
-0.5 \\
0 \\
0.5 \\
1 \\
0.5 \\
-0.5 \\
1 \\
0.5 \\
-0.5\end{array}$ & $\begin{array}{r}-0.37 \\
0.66 \\
-0.82 \\
-0.97 \\
0.15 \\
0.22 \\
0.67 \\
0.72 \\
0.17 \\
0.73 \\
0.94 \\
-1.07 \\
0.84 \\
0.30 \\
-0.71\end{array}$ \\
\hline $\begin{array}{l}\text { error } \\
\text { total }\end{array}$ & $\begin{array}{r}58.72 \\
286.26\end{array}$ & $\begin{array}{l}15 \\
32\end{array}$ & 3.67 & \multicolumn{3}{|c|}{$\sigma_{1}^{2}+\sigma_{2}^{2}=4.25$} \\
\hline
\end{tabular}


model in RACOFFD

(4)

\begin{tabular}{|c|c|c|c|c|c|c|c|c|c|c|c|c|c|c|c|c|c|}
\hline $\begin{array}{l}\beta 1 \\
0\end{array}$ & $\begin{array}{l}2 \\
0\end{array}$ & $\begin{array}{l}3 \\
0\end{array}$ & $\begin{array}{c}4 \\
0.5\end{array}$ & $\begin{array}{c}5 \\
0.5\end{array}$ & $\begin{array}{c}6 \\
0.5\end{array}$ & $\begin{array}{c}7 \\
-0.5\end{array}$ & $\begin{array}{c}8 \\
0.5\end{array}$ & $\begin{array}{l}9 \\
0\end{array}$ & $\begin{array}{r}10 \\
-0.5\end{array}$ & $\begin{array}{l}11 \\
0.5\end{array}$ & $\begin{array}{l}12 \\
-1\end{array}$ & $\begin{array}{l}13 \\
0.5\end{array}$ & $\begin{array}{c}14 \\
0\end{array}$ & $\begin{array}{r}15 \\
-0.5\end{array}$ & $v_{n}$ & $\varepsilon_{n}$ & $y_{n}$ \\
\hline $\begin{array}{l}0 \\
1 \\
0 \\
0 \\
0 \\
1 \\
1 \\
1 \\
0 \\
0\end{array}$ & $\begin{array}{l}1 \\
1 \\
0 \\
0 \\
0 \\
1 \\
0 \\
0 \\
1 \\
1\end{array}$ & $\begin{array}{l}0 \\
1 \\
0 \\
0 \\
1 \\
0 \\
1 \\
0 \\
1 \\
0\end{array}$ & $\begin{array}{l}1 \\
0 \\
1 \\
1 \\
0 \\
0 \\
0 \\
1 \\
1 \\
0\end{array}$ & $\begin{array}{l}0 \\
1 \\
0 \\
1 \\
1 \\
1 \\
0 \\
1 \\
1 \\
1\end{array}$ & $\begin{array}{l}1 \\
0 \\
1 \\
0 \\
0 \\
1 \\
1 \\
0 \\
1 \\
1\end{array}$ & $\begin{array}{l}0 \\
0 \\
1 \\
1 \\
1 \\
1 \\
1 \\
1 \\
1 \\
1\end{array}$ & $\begin{array}{l}1 \\
1 \\
0 \\
1 \\
0 \\
0 \\
1 \\
1 \\
1 \\
0\end{array}$ & $\begin{array}{l}0 \\
0 \\
1 \\
0 \\
1 \\
0 \\
0 \\
0 \\
1 \\
0\end{array}$ & $\begin{array}{l}1 \\
1 \\
0 \\
0 \\
1 \\
0 \\
0 \\
1 \\
0 \\
1\end{array}$ & $\begin{array}{l}0 \\
0 \\
1 \\
1 \\
0 \\
0 \\
1 \\
0 \\
0 \\
1\end{array}$ & $\begin{array}{l}1 \\
1 \\
0 \\
1 \\
1 \\
1 \\
1 \\
0 \\
0 \\
0\end{array}$ & \begin{tabular}{l|l}
0 & \\
0 \\
1 \\
0 \\
0 \\
1 \\
0 \\
1 \\
1 \\
0 \\
0
\end{tabular} & $\begin{array}{l}1 \\
0 \\
1 \\
1 \\
1 \\
1 \\
0 \\
0 \\
0 \\
0\end{array}$ & $\begin{array}{l}0 \\
1 \\
0 \\
1 \\
0 \\
0 \\
0 \\
0 \\
0 \\
1\end{array}$ & $\begin{array}{r}1.5 \\
1.5 \\
-1.5 \\
-0.5 \\
2.5 \\
1.5 \\
1.5 \\
-2.5 \\
-1.5 \\
1.5\end{array}$ & $\begin{array}{r}-0.8 \\
0.4 \\
-1.2 \\
-1.4 \\
0.2 \\
1.2 \\
0.6 \\
-1.8 \\
1.3 \\
0.6\end{array}$ & $\begin{array}{r}2.7 \\
1.9 \\
-3.7 \\
1.1 \\
1.7 \\
3.7 \\
2.1 \\
-4.3 \\
0.8 \\
5.1\end{array}$ \\
\hline $\begin{array}{l}1 \\
0 \\
0 \\
0 \\
1 \\
0 \\
1 \\
1 \\
1 \\
1\end{array}$ & $\begin{array}{l}1 \\
1 \\
0 \\
0 \\
0 \\
1 \\
0 \\
1 \\
0 \\
1\end{array}$ & $\begin{array}{l}1 \\
0 \\
0 \\
1 \\
1 \\
1 \\
0 \\
1 \\
0 \\
1\end{array}$ & $\begin{array}{l}1 \\
1 \\
0 \\
1 \\
1 \\
0 \\
0 \\
0 \\
0 \\
1\end{array}$ & $\begin{array}{l}0 \\
1 \\
0 \\
1 \\
1 \\
0 \\
0 \\
0 \\
1 \\
1\end{array}$ & $\begin{array}{l}0 \\
0 \\
0 \\
1 \\
1 \\
1 \\
0 \\
1 \\
1 \\
1\end{array}$ & $\begin{array}{l}1 \\
0 \\
0 \\
0 \\
0 \\
0 \\
0 \\
0 \\
0 \\
1\end{array}$ & $\begin{array}{l}0 \\
0 \\
0 \\
0 \\
0 \\
0 \\
0 \\
0 \\
1 \\
1\end{array}$ & $\begin{array}{l}0 \\
1 \\
0 \\
0 \\
0 \\
1 \\
0 \\
1 \\
1 \\
1\end{array}$ & $\begin{array}{l}1 \\
1 \\
0 \\
1 \\
0 \\
0 \\
1 \\
1 \\
1 \\
1\end{array}$ & $\begin{array}{l}1 \\
0 \\
0 \\
1 \\
0 \\
1 \\
1 \\
0 \\
1 \\
1\end{array}$ & $\begin{array}{l}0 \\
0 \\
0 \\
1 \\
0 \\
1 \\
1 \\
0 \\
0 \\
1\end{array}$ & $\begin{array}{l}0 \\
1 \\
0 \\
1 \\
0 \\
0 \\
1 \\
1 \\
0 \\
1\end{array}$ & 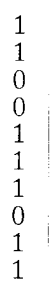 & $\begin{array}{l}0 \\
1 \\
0 \\
0 \\
1 \\
1 \\
1 \\
0 \\
0 \\
1\end{array}$ & $\begin{array}{r}-0.5 \\
-1.5 \\
-0.5 \\
-0.5 \\
-0.5 \\
2.5 \\
1.5 \\
0.5 \\
-1.5 \\
0.5\end{array}$ & $\begin{array}{r}0.5 \\
0.5 \\
-0.3 \\
0.1 \\
0.9 \\
1.0 \\
1.3 \\
-1.3 \\
1.5 \\
1.8\end{array}$ & $\begin{array}{r}-4.0 \\
-1.0 \\
-4.8 \\
-2.4 \\
-0.6 \\
-1.5 \\
0.8 \\
-0.8 \\
1.0 \\
-0.7\end{array}$ \\
\hline $\begin{array}{l}1 \\
0 \\
1 \\
0 \\
0 \\
1 \\
1 \\
0 \\
1 \\
0\end{array}$ & $\begin{array}{l}1 \\
1 \\
0 \\
0 \\
0 \\
1 \\
0 \\
0 \\
0 \\
1\end{array}$ & $\begin{array}{l}0 \\
0 \\
1 \\
0 \\
1 \\
0 \\
1 \\
1 \\
0 \\
1\end{array}$ & $\begin{array}{l}1 \\
0 \\
0 \\
0 \\
0 \\
0 \\
1 \\
1 \\
1 \\
1\end{array}$ & $\begin{array}{l}1 \\
0 \\
1 \\
1 \\
0 \\
0 \\
0 \\
0 \\
0 \\
0\end{array}$ & $\begin{array}{l}0 \\
0 \\
0 \\
1 \\
1 \\
0 \\
0 \\
0 \\
1 \\
0\end{array}$ & $\begin{array}{l}0 \\
1 \\
1 \\
0 \\
1 \\
1 \\
0 \\
0 \\
1 \\
1\end{array}$ & $\begin{array}{l}0 \\
1 \\
0 \\
1 \\
1 \\
1 \\
1 \\
1 \\
0 \\
0\end{array}$ & $\begin{array}{l}1 \\
1 \\
1 \\
1 \\
0 \\
1 \\
1 \\
1 \\
1 \\
0\end{array}$ & $\begin{array}{l}0 \\
1 \\
0 \\
0 \\
1 \\
0 \\
0 \\
1 \\
1 \\
0\end{array}$ & $\begin{array}{l}1 \\
1 \\
1 \\
0 \\
0 \\
0 \\
0 \\
1 \\
0 \\
0\end{array}$ & $\begin{array}{l}1 \\
1 \\
0 \\
1 \\
0 \\
0 \\
1 \\
0 \\
1 \\
1\end{array}$ & $\begin{array}{l}0 \\
1 \\
1 \\
1 \\
1 \\
0 \\
1 \\
0 \\
0 \\
1\end{array}$ & \begin{tabular}{l|l}
0 & \\
0 & \\
0 & \\
0 & \\
1 & \\
1 & \\
1 & \\
0 & \\
0 & \\
0 &
\end{tabular} & $\begin{array}{l}0 \\
0 \\
1 \\
1 \\
1 \\
1 \\
0 \\
1 \\
1 \\
1\end{array}$ & $\begin{array}{r}-1.5 \\
0.5 \\
-1.5 \\
0.5 \\
1.5 \\
0.5 \\
-1.5 \\
-1.5 \\
4.5 \\
1.5\end{array}$ & $\begin{array}{r}0.4 \\
0.5 \\
0.2 \\
1.1 \\
1.6 \\
-1.9 \\
0.7 \\
-2.6 \\
-0.5 \\
0.8\end{array}$ & $\begin{array}{r}-0.1 \\
0 \\
-1.3 \\
1.6 \\
2.1 \\
-4.4 \\
3.2 \\
-4.1 \\
8.0 \\
4.3\end{array}$ \\
\hline $\begin{array}{l}0 \\
1\end{array}$ & $\begin{array}{l}1 \\
1\end{array}$ & $\begin{array}{l}1 \\
0\end{array}$ & $\begin{array}{l}0 \\
1\end{array}$ & $\begin{array}{l}1 \\
0\end{array}$ & $\begin{array}{l}0 \\
1\end{array}$ & $\begin{array}{l}0 \\
0\end{array}$ & $\begin{array}{l}1 \\
1\end{array}$ & $\begin{array}{l}0 \\
0\end{array}$ & $\begin{array}{l}0 \\
0\end{array}$ & $\begin{array}{l}1 \\
1\end{array}$ & $\begin{array}{l}0 \\
0\end{array}$ & $\begin{array}{l}1 \\
1\end{array}$ & $\begin{array}{l}1 \\
0\end{array}$ & $\begin{array}{l}0 \\
1\end{array}$ & $\begin{array}{l}-4.5 \\
-2.5\end{array}$ & $\begin{array}{r}1.3 \\
-1.2\end{array}$ & $\begin{array}{r}-2.2 \\
1.3\end{array}$ \\
\hline
\end{tabular}

TABLE 2-12 Analysis of variance in RACOFFD

2nd group

\begin{tabular}{|c|c|c|c|c|c|c|}
\hline Parameters & S. S & D. $F$ & M.S & $\mathrm{F}_{0}$ & Value of $\beta_{r}$ & $\hat{\beta}_{r}$ \\
\hline $\begin{array}{r}1 \\
2 \\
3 \\
4 \\
5 \\
6 \\
7 \\
8 \\
9 \\
10 \\
11 \\
12 \\
13 \\
14 \\
15\end{array}$ & $\begin{array}{r}1.16 \\
0.69 \\
2.26 \\
0.63 \\
0.30 \\
31.80 \\
7.51 \\
0.05 \\
2.05 \\
1.32 \\
16.10 \\
69.92 \\
0.58 \\
2.59 \\
12.13\end{array}$ & $\begin{array}{l}1 \\
1 \\
1 \\
1 \\
1 \\
1 \\
1 \\
1 \\
1 \\
1 \\
1 \\
1 \\
1 \\
1 \\
1\end{array}$ & $\begin{array}{r}1.16 \\
0.69 \\
2.26 \\
0.63 \\
0.30 \\
31.80 \\
7.51 \\
0.05 \\
2.05 \\
1.32 \\
16.10 \\
69.92 \\
0.58 \\
2.59 \\
12.13\end{array}$ & $\begin{array}{r}0.14 \\
0.08 \\
0.26 \\
0.07 \\
0.04 \\
* 3.71 \\
0.88 \\
0.01 \\
0.24 \\
0.15 \\
* 1.88 \\
* 8.16 \\
0.07 \\
0.30 \\
1.42\end{array}$ & $\begin{array}{c}0 \\
0 \\
0 \\
0.5 \\
0.5 \\
-0.5 \\
-0.5 \\
0.5 \\
0 \\
-0.5 \\
0.5 \\
-1 \\
0.5 \\
0 \\
-0.5\end{array}$ & $\begin{array}{r}-0.19 \\
-0.15 \\
0.27 \\
0.14 \\
-0.10 \\
-1.00 \\
-0.48 \\
0.04 \\
0.25 \\
-0.20 \\
0.71 \\
-1.48 \\
0.13 \\
0.28 \\
0.62\end{array}$ \\
\hline $\begin{array}{l}\text { error } \\
\text { total }\end{array}$ & $\begin{array}{l}137.17 \\
286.26\end{array}$ & $\begin{array}{l}15 \\
32\end{array}$ & 8.57 & \multicolumn{3}{|c|}{$\sigma_{1}^{2}+\sigma_{2}^{2}=6.50$} \\
\hline
\end{tabular}



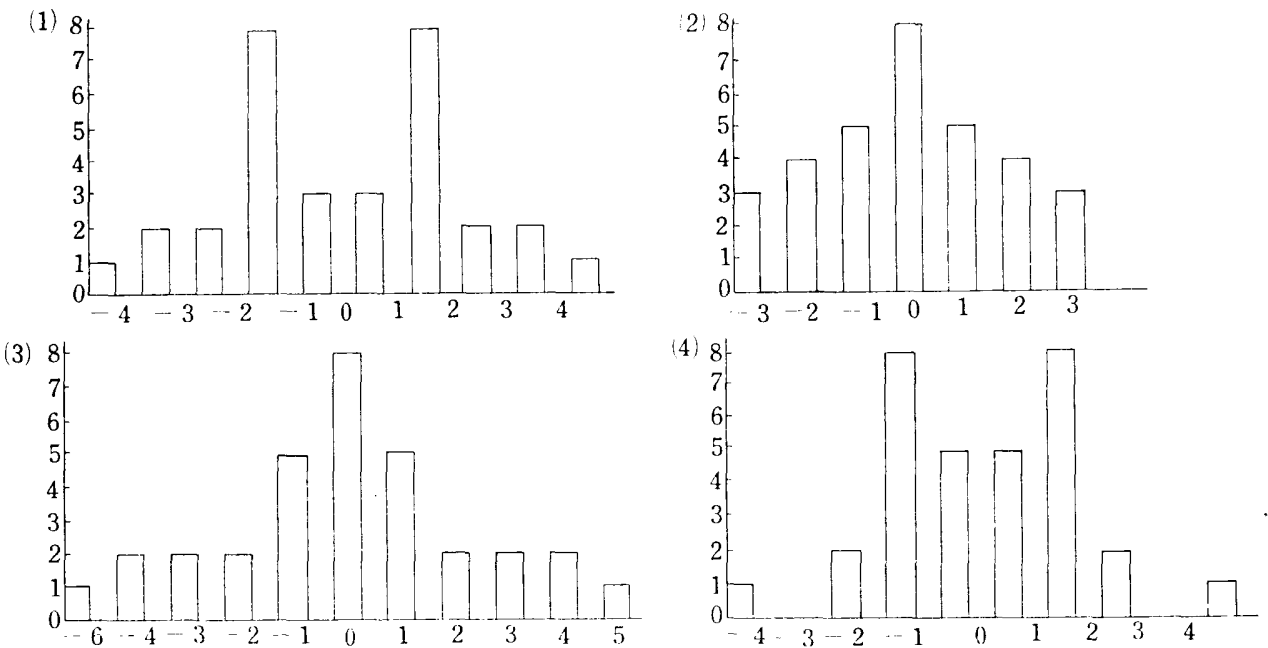

FIG. 2-10 Finite populations in our synthetic models

where

$$
\begin{aligned}
& x_{0}=\frac{\nu_{p} k_{p}^{-1} F_{\phi}^{1}\left(\alpha_{0}\right)}{\Phi+\nu_{p} k_{p}^{-1} F_{\phi}^{1}\left(\alpha_{0}\right)} \\
& \nu_{p}=\frac{\left(1+2 \tau_{p}\right)^{2}}{1+4 \tau_{p}}
\end{aligned}
$$

in which

$$
k_{p}=1+2 \tau_{p}, \tau_{p}=N \alpha_{p}^{2} / 2\left(1+\mu_{2}\right) \text {. }
$$

In the example of the models, we have finite populations as a noisy effect in our synthetic models in the Fig. 2-10, in which populations (1), (2), (3) and (4) are corresponding to the synthetic populations, the (1) which is given in the 17 th column $\zeta_{n}$ of Table $2-7$, the (2) given in the 3 rd column from the last $v_{n}$ of Table 2-7, the (3) given in the 17 th column $\zeta_{n}$ of Table 2-10, and the (4) given in the 3rd column from the last $v_{n}$ of Table 2-10, Then we can get the asymptotic power of test, which are given by

$$
\begin{array}{rr|r|r|r|r}
\text { for } & 1 \mathrm{st} & 2 \mathrm{nd} & 3 \mathrm{rd} & 4 \text { th } & \text { analysis variance table } \\
\tau_{p}= & 4.34 & 2.78 & 3.76 & 2.46 & \text { for } \alpha_{p}=1.0 \\
= & 1.08 & 0.70 & 0.94 & 0.62 & \text { for } \alpha_{p} !=0.5
\end{array}
$$

and the 2nd kind of error in the following table for $\Phi=15$ and $\alpha_{0}=0.20$.

Furthermore, the estimates of the parameters are given in the last columns in the analysis of variance tables. From these, it can be observed that the estimates of the parameters in the RACOFFD methods are distributed in a wide range. 


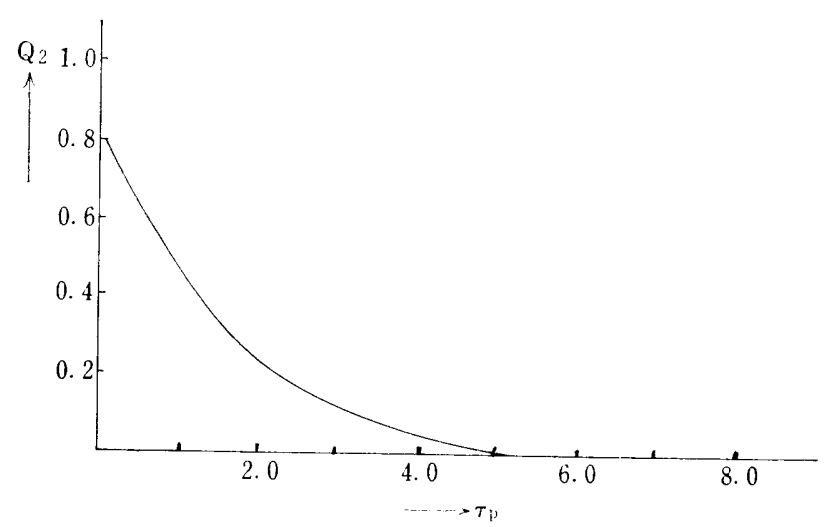

FIG. $2-11$ The 2 nd kind of error for $\Phi=15$ and $\alpha_{0}=0.20$

\section{Acknowledgements}

The author expresses his gratitude to Professor Kitagawa for his helpfull guidance of full course of this research and kind encouragements. His gratiture is also due to Dr. Shimada for his helpfull suggestions and kind encouragements, and also due to many members of Kasado Works, Hitachi Ltd. for practical applications of this RACOFFD method and carrying through a large scale numerical computation.

\section{References}

[1] Anscombe, F. J.; Quick analysis methods for random balance screening experiments, Technometrics 1 (1959), 195-209.

[2] Bangroft, T. A.; On bases in estimation due to the use of preliminary tests of significance, Ann. Math. Statist. 15 (1944), 190-204.

[ 3 ] Box, G. E. P. and BehnkeN, D. W.; Simplex-sum designs; a class of second order rotatable designs derivable from those of first order, Ann. Math. Statist. 31 (1960) 834-864.

[4] Box, G. E. P. and Hunter, J. S.; Multi-factor experimental designs for exploring response surfaces, Ann. Math. Statist. 28 (1957), 195-241.

[ 5 ] Box, G. E. P. and Hunter, J. S. ; The $2^{K-P}$ fractional factorial designs Part I, Technometrics 3 (1961), 311-351.

[ 6 ] Box, G. E. P. and Hunte?, J. S. ; The $2^{K-P}$ fractional factorial designs Part II, Technometrics 3 (1961) 449-458.

[ 7 ] Bozivich, H., Bangroft, T. A. and Hartley, H. O.; Power of analysis of variance test procedures for certain incompletely specified models I, Ann. Math. Statist. 27 (1956), 1017-1043.

[8] Ввоокs, S.; Comparison of methods for estimating the optimal factor combination, Thesis approved for the degree of doctor of Science in Hygience (April-1955).

[9] Budne, T. A.; The application of random balance designs, Technometrics 1 (1959), 139155.

[10] Dempster, A. P. ; Random allocation designs I: On general classes of estimation methods, Ann. Math. Statist. 31 (1960), 885-905.

[11] Dempster, A. P.; Random allocation designs II: Approximate theory for simple random allocations, Ann. Math. Statist. 32 (1961), 378-405. 
[12] Hоове, R.; Symmetric function of a two-way array, Ann. Math. Statist. 27 (1956), 55-79.

[13] НоовЕ, R.; Some applications of bipolykays to the estimation of variance components and their moments, Ann. Math. Statist. 27 (1956), 80-98.

[14] Kitagawa, T.; Successive process of statistical inferences, Mem. Fac. Sci. Kyushu University, Series A, 15 (1950) 139-180.

[15] KitásaWa, T.; The lecture of design of experiments I Baifukan (1955) 1-335 (in Japanese).

[16] Kitagawa, T.; Successive process of statistical inferences, Applied Mathematics Colloquium, Series B, 10a, Iwanami (1958), 1-121.

[17] KitagaWA, T.; Successive process of statistical inferences applied to linear regression analysis and its specializations to response surface analysis, Bull. Math. Statist., 8 (1959), 80-114.

[18] Kitagawa, T. ; Estimation after preliminary tests of significance, Univ. Calif. Pub. in Statist. 3 (1963), 147-186.

[19] MaNn, H. B.; Analysis and design of experiments, Dover Pub., Inc., (1949), 1-77.

[20] Moriguchi, S. ; Statistical Analysis, Applied Mathematics Colloquium, Series B. 10b, Iwanami (1958), 1-94.

[21] РАTNaIK, Р. В.; The non-central $\chi^{2}$ - and F-distributions and their applications, Biometrika 39 (1949), 202-232.

[22] PAULL, A. E.; On a preliminary test for pooling mean squares in the analysis of variance, Ann. Math. Statist. 21 (1950), 539-556.

[23] PEARson, K.; Table of the incomplete beta-function, the Biometrika office, London, (1948), $1-494$.

[24] Plackett, R. L. and Burman, J. P. ; The design of optimum multifactorial experiments, Biometrika, 33 (1946), 305-325.

[25] Satterthwatte, F. E.; Random balance experimentation, Technometrics 1 (1959) 31-54.

[26] Shimada, S.; Introduction to stochastics (1955) Denki-Shoin, (in Japanese)

[27] TAGUCH, G. ; Design of experiments I. (1957) Maruzen (in Iapanese)

[28] TAGUCH, G. ; Design of experiments II, (1957) Maruzen, (in Japanese)

[29] ТАКЕUСНТ, K.; On a special class of regression problems and its apptications; Random combined fractional factorial designs, Rep. Statist. Appl. Res. J. U. S. E., 7 (1960) 167-198.

[30] ТАКEUCH, K.; On a special class of regression problems and its applications; Rondom combined fractional factorial designs, (continued) Part II The case for $r \geqq 3$, Rep. Statist. App1. Res. J.U.S.E. 8 (1961), 1-6.

[31] ТАВЕटCHI, K.; On a special class of regression problems and its application; Some remarks about general models, Rep. Statist. Res, J. U. S. E., 8 (1961), 7-17.

[32] Turex, J. W. ; Some sampling simplified, Jour. Amer. Statist. Assoc., 45 (1950), 501-519.

[33] Тикеу, J. W.; Keepinz moment-like sampling computations simple, Ann. Math. Statist. 27 (1956) $37-54$.

[34] Yамақаша, N.; Random combined fractional factorial designsII : Sampling theory from the finite populations, submitted for publication in the Bull, Math. Statist. 